\title{
La mayoría de edad como presunción iuris tantum de capacidad en los códigos civiles y canónicos
}

\author{
The Age of Majority as a Presumption iuris tantum \\ of Capacity in Civil and Canonical Codes
}

\section{Jorge Castro Trapote}

Doctor en Derecho

Universidad de Zaragoza. Zaragoza

orcid 0000-0003-1506-3023

trapotejc@gmail.com
Resumen: Los distintos códigos civiles y canónicos heredan el sistema de capacidad de obrar basado en la edad legal iniciado en el Derecho romano, pero una parte considerable de la doctrina cambia su naturaleza jurídica al interpretar la norma de la mayoría de edad en sentido positivista como frontera que separa a las personas en capaces e incapaces. Esto implica un sistema rígido y poco realista en el que se descarta la 'vigencia' de la capacidad natural una vez promulgada la norma de la mayoría de edad legal civil o canónica. Como respuesta, emergen posiciones doctrinales 'naturalistas' que postulan un reconocimiento legal directo de la capacidad natural o escalonada en múltiples tramos de edades. Al lado de estos extremos, y en continuidad con la tradición jurídico-clásica, la mayoría de edad legal puede ser entendida como presunción iuris tantum, permitiendo así que toda persona con capacidad natural pueda actuar con eficacia jurídica de un modo viable y seguro.

Palabras clave: Capacidad, Mayoría de edad, Presunción iuris tantum, Realismo jurídico.
Abstract: Civil and canonical codes have inherited the capacity-to-act system based on the definition of legal age set out in Roman law. However, a significant part of (both civil and canonical) jurisprudence alters its legal status by interpreting the rule of age of majority in a positivist sense, as a dividing line between those with capacity and those without. This approach sets up a rigid and unrealistic system in which the 'validity' of natural capacity is excluded once the rule of legal civil or canonical age of majority has been established. 'Naturalistic' perspectives have emerged in response, proposing a direct recognition of natural or tiered capacity in multiple age brackets. Apart from these opposing positions, and in line with the classical legal tradition, the legal age of majority may be read as a presumption of iuris tantum, thus allowing any person with natural capacity to act, with legal efficacy, in a viable and certain way.

Keywords: Capacity, Age of Majority, Presumption of iuris tantum, Legal Realism. 


\section{INTRODUCCIÓN}

a capacidad de obrar es una cuestión fundamental en los ordenamientos que hace referencia al ejercicio de los derechos y deberes, y por ello los autores han mantenido una reflexión constante sobre este aspecto básico del Derecho de la persona. En la actualidad, los interrogantes vienen planteados sobre el tema de la capacidad de los menores y discapaces, y a consecuencia de ello, se ha sometido a revisión la habitual interpretación de la norma de la mayoría de edad prevista en los códigos civiles y canónicos (en los actuales y en los anteriores, tanto en la redacción inicial como en las reformas posteriores), que tiene su origen en la identificación que Savigny hace entre la mayoría de edad y la capacidad natural mínima para actuar por uno mismo, y que conduce a la consideración de la minoría de edad como circunstancia impeditiva de la capacidad de obrar ${ }^{1}$. Esta interpretación, lleva a concluir la existencia de un principio de incapacidad general del menor, salvo en los casos expresamente previstos por la ley.

Frente a esta interpretación reaccionó Federico de Castro, que consideraba necesario ofrecer un soporte legal a una capacidad de obrar limitada de los menores, en continuidad con la tradición jurídico-realista. Más allá de la solución que De Castro adoptó por medio del estado civil de la minoría de edad, hoy sin base legal en el Código civil español, ha ejercido una gran influencia entre los civilistas, hasta el punto de convertirse en mayoritaria la doctrina que sostiene la necesidad de encontrar una previsión legal general a la capacidad natural de los menores ${ }^{2}$, que de momento se está llevando a cabo puntualmente para determinados actos o negocios jurídicos. Junto a ello han surgido propuestas de reducir los años de la mayoría de edad, o de reconocer la capacidad natural de cada persona prescindiendo de la norma de la mayoría de edad prevista en los códigos.

Por este motivo, considero oportuno replantear la naturaleza jurídica de la norma de la mayoría de edad, y en concreto, proponer una alternativa a la interpretación comúnmente aceptada desde los inicios de la codificación: ¿es una norma positivista en el sentido de marcar una frontera entre la capacidad (mayores de edad) y la incapacidad de obrar (menores de edad) con independencia

${ }^{1}$ Cfr. F. C. Di Savigny, Sistema de Diritto romano attuale. Volumen terzo, Traducción di Scialoja, UTET, Torino ${ }^{2} 1900,23$.

2 Cfr. F. De Castro y Bravo, Derecho civil de España. Tomo II. Derecho de la persona. Parte primera. La persona y su estado civil, Instituto de estudios políticos, Madrid 1952, 61. 
de la capacidad natural concreta de una persona determinada, o se trata de una norma que establece una presunción iuris tantum que permite el ejercicio de los derechos y deberes cuando la capacidad natural específica de una persona queda acreditada al margen de su edad? La mayoría de edad como presunción iuris tantum puede ofrecer, desde mi punto de vista, un respaldo legal a la capacidad de los menores que respetaría las exigencias de la seguridad jurídica.

El presente artículo se centra en la naturaleza jurídica de la mayoría de edad que todos los códigos prevén en sus normas generales, sin que haya podido encontrar uno que renuncie a ese modo de regular la capacidad de obrar de las personas físicas iniciado por el Código civil francés ${ }^{3}$. Si bien existen reformas rebajando la edad de la mayoría, sigue girando en torno a ésta la estructuración básica de la capacidad de obrar. Es por ello que las referencias que el artículo contiene a la codificación civil y canónica, han de entenderse efectuadas tanto a las normas vigentes, como a las regulaciones anteriores, puesto que desde la redacción originaria de cada código civil y canónico, la técnica de la mayoría de edad ha seguido estando presente. Igualmente, las reflexiones alcanzan, a modo de planteamiento, a las edades legales específicamente señaladas para algunos actos o negocios jurídicos en el ámbito civil o canónico, si bien veo necesario un estudio específico de cada una de ellas que en el presente artículo no se lleva a cabo. Por otro lado, considero adecuado un tratamiento conjunto del ámbito civil y canónico, no sólo porque la técnica de la mayoría de edad es compartida, sino porque existe una importante remisión en materia de capacidad de los menores a la ley nacional del bautizado.

En el aspecto doctrinal existe una amplia coincidencia entre teóricos del Derecho, civilistas y canonistas, en tanto que las cuestiones técnicas y de fondo que se plantean son comunes. No obstante, como la demanda de una mayor consideración de la capacidad natural de los menores ha provocado un replanteamiento de la norma de la mayoría, existe una oportunidad de revisar los postulados positivistas con los que se inició, a mi juicio, la interpretación de la norma de la mayoría de edad en el ámbito civil, y que hasta ahora no ofrecía dudas porque los desajustes con la capacidad natural no eran considerados relevantes ni en el ámbito civil ni en el canónico. En mi opinión, es una ocasión

\footnotetext{
3 Artículo 488 Código civil francés. La técnica de la mayoría de edad aparece en todos los códigos que he podido consultar, como por ejemplo en los cánones 97 y 98 Código de Derecho canónico de 1983; artículos 315 y 322 Código civil español; artículo 2 Código civil italiano; artículos 24 y 25 Código civil argentino.
} 
para que la reflexión canónica prosiga en la teoría de la capacidad de obrar los avances efectuados en la teoría del sujeto de derecho y de la capacidad jurídica, donde ha llevado a cabo valiosas aportaciones, guiadas por el realismo jurídico, para el Derecho en general. Adoptaré por tanto una posición jurídico-realista en la alternativa propuesta, que comporta el intento de lograr un mayor ajustamiento a la capacidad natural, una mayor justicia en el caso concreto, y ello sin ceder en las exigencias de la seguridad jurídica. De este modo intentaré corregir los postulados positivistas, que serían aquellos que no tienen en cuenta las diferencias "reales" de capacidad entre las personas, al concluir por ejemplo, que los menores de 1 y 17 años son igualmente incapaces como regla general.

Pero, ¿qué interés puede tener más allá del estrictamente teórico? Como el estudio se refiere en general a los códigos, pero también al sistema de capacidad de obrar previsto en el Código de Derecho canónico de 1983 y en los códigos civiles actuales, las conclusiones repercutirán en el efectivo ejercicio de los derechos y obligaciones en el ámbito civil y en el ámbito canónico. Es aquí donde radica la importancia práctica de la naturaleza jurídica de la mayoría de edad: depende de la solución que se adopte, se estará concluyendo la nulidad o validez de los actos civiles y canónicos realizados por una persona. En concreto, se afrontan las siguientes cuestiones: ¿tienen la misma capacidad de obrar legal el recién nacido y el menor de 15 años?; ¿es nulo de pleno derecho el acto jurídico realizado por un menor con capacidad natural pero sin capacidad de obrar legal?; ¿conserva algún valor jurídico la capacidad natural del menor en los distintos códigos más allá de servir de referencia a la producción de las normas?; ¿por qué no son nulos radicalmente en los ordenamientos (civiles y canónico) los actos realizados por el menor cuando disponía de capacidad natural pero no de capacidad de obrar legal? Al afrontar estas cuestiones, y dejando a un lado valiosas aportaciones casuísticas, he preferido buscar la comprensión conjunta del sistema de capacidad de obrar que actualmente sigue estructurado sobre la norma de mayoría de edad.

Para ello he seguido el siguiente iter argumental. Al inicio me detengo en el concepto de la capacidad de obrar y sus elementos, sobre los que existe un amplio acuerdo doctrinal. Posteriormente paso a examinar las diversas propuestas (positivista, naturalista, jurídico-realista) que existen para estructurar legalmente la capacidad de obrar, señalando sus ventajas e inconvenientes; y en concreto, propongo recuperar la alternativa elaborada en el Derecho romano por los jurisconsultos: la técnica de la mayoría de edad como presunción. En mi opinión, esta opción sería la más adecuada para expresar codicial- 
mente y de forma viable el elemento esencial de la capacidad de obrar apuntado por los civilistas y canonistas: la capacidad natural. A continuación, intentaré mostrar que es posible calificar como presunción iuris tantum la norma de la mayoría de edad prevista en los códigos. Luego examinaré si la mayoría de edad contiene los elementos que la doctrina procesalista señala en toda presunción iuris tantum. Finalmente, señalaré una serie de perspectivas que, a mi juicio, quedan abiertas y pendientes de estudio en el caso de compartirse la presunción iuris tantum como naturaleza jurídica de la mayoría de edad, por ejemplo, si es extensible como solución a cualquier otra edad específicamente señalada para un acto o negocio jurídico concreto.

\section{Conceptos y ELEMENTOS DE LA CAPACIDAD DE OBRAR}

Aunque son muchas las cuestiones disputadas en materia de capacidad de obrar $^{4}$, la doctrina alcanza uno de los puntos de entendimiento en el momento de su definición. En concreto, los autores, tanto civilistas como canonistas, señalan que la esencia de la capacidad de obrar consiste en el ejercicio "por sí mismo" con eficacia jurídica de los derechos y obligaciones. Por lo tanto, la doctrina mayoritaria conecta la capacidad de obrar con la llamada 'capacidad natural' 5

\footnotetext{
${ }^{4}$ Cfr. P. STANZIONe, Capacità e minore età nella problematia della persona umana, Jovene Editore, Camerino 1976, 149.

5 Cfr. J. L. Lacruz Berdejo - J. Delgado Echeverría, Elementos de Derecho Civil. I. Parte general. Volumen II. Personas, Dykinson, Madrid '2010, 4; cfr. B. WINDSCHEID, Diritto delle pandette, Unione Tipografica Editrice, Milano 1902, 219; cfr. H. NaWiansky, Teoría general del Derecho, Comares, Granada 2002, 248; cfr. F. CARnELUTTI, Notas sobre la capacidad y la incapacidad, Revista de Derecho Privado 37 (1953) 949-956; cfr. C. MartíneZ DE AguirRe y AldaZ, La persona y el Derecho de la persona, en P. De Pablo Contreras (coord.), Curso de Derecho civil. Volumen I. Derecho privado. Derecho de la persona, Colex, Madrid '2011, 326; cfr. J. CASTÁn ToBeÑas, Derecho civil español, común y foral. Tomo I. Introducción y parte general. Volumen II, Reus, Madrid ${ }^{15} 2007,151$; cfr. J. A. Doral García, La personalidad jurídica. De la libertad formal a la libertad civil, Revista de Derecho Privado 61 (1977) 112; cfr. F. FERRARA, Trattato di diritto civile italiano. Volumen I. Dottrine generali. Parte I, Athenaeum Roma, 1921, 459-460; cfr. A. FALZEA, «Capacitá. Teoria generale», en F. Calasso (dir.), Enciclopedia del diritto, VI, Giuffrè Editore, Varese 1960, 38; cfr. C. Gangi, Persone fisiche e persone giuridiche, Giuffrè, Milano 1946, 7; cfr. A. RavÀ, Istituzioni di diritto privato. II. Diritto delle persone, CEDAM, Padova ${ }^{5} 1932$, 49; cfr. R. DE RUGGIERO, Istitutioni di diritto civile, Principato, Milano 1953, 174; cfr. R. Bercovitz y Rodríguez Cano, Derecho de la persona, Montecorvo, Madrid 1976, 11; cfr. F. C. DE DiEgo, Curso elemental de Derecho civil español común y foral. Tomo $2^{\circ}$. Parte General, Victoriano Suárez, Madrid 1927, 76; cfr. A. GordiLlo CAÑAS, Capacidad, incapacidades y estabilidad de los contratos, Tecnos, Madrid 1986, 39; cfr. C. VALverde y Valverde, Tratado de derecho español. Tomo I. Parte General, Cuesta, Valladolid ${ }^{3} 1925$, 258-260, 273. En el ámbito canónico se reproduce la doctrina civil: cfr. G. Michiels, Principia Generalia de personis in Ecclesia, S. Joannis Evangelistae, Roma 1955, 37; cfr. A. BLAT, Comenta-
} 
Una vez que se ha identificado la esencia de la capacidad de obrar, la pregunta que los autores plantean a continuación es la siguiente: ¿cómo se individualiza la capacidad natural? La doctrina describe dos vías de concreción: 1) Generalmente y como punto de partida por medio de la edad natural a la que está conectado el desarrollo de las capacidades personales. 2) Excepcionalmente por medio de un previo examen de la enfermedad en tanto que afecte al estado normal de esas capacidades. Estos elementos que se distinguen en la capaciad natural -la edad y la enfermedad- son la base para determinar la capacidad de obrar desde el Derecho romano ${ }^{6}$ hasta la actualidad. La edad de modo positivo y general, y la enfermedad de modo negativo y particular.

Ahora me centraré en la edad por ser la regla general y un hito doctrinal en la historia. Quizá nos parezca imprescindible como elemento jurídico en la doctrina y en los ordenamientos, pero lo cierto es que la edad era desconocida en un principio en la determinación de la capacidad 7 . Ésta siempre ha sido lo mismo a lo largo de la historia, es decir, una capacidad psicológica y corporal, una aptitud humana para llevar a cabo actos por sí mismo en la vida civil o eclesiástica. Pero la forma de concretar la capacidad natural no ha sido siempre igual, ni la edad fue el primer modo. La cuestión era determinar quién podía actuar con relevancia jurídica -quién tenía capacidad de obrar-; y, dejando al margen otras limitaciones -alieni iuris-, ostentaba capacidad de obrar quien tenía la capacidad natural detectada por diversos criterios según el genio jurídico del pueblo en cuestión: para los romanos fue la capacidad de la pubertad ${ }^{8}$,

rium textus Codicis iuris canonici. Liber II. De personis, Editio altera, Roma 1921, 8; cfr. M. PETroncelli, Diritto canonico, Jovene, Nápoles ${ }^{8} 1983,80$; cfr. A. De FuenmaYor, sub c. 98, Comentario exegético al Código de Derecho canónico, I, Eunsa, Pamplona 32002, 726; cfr. J. FerRer ORTIZ, Los sujetos del Ordenamiento canónico, en Manual de Derecho canónico, Eunsa, Pamplona 1988, 153; cfr. G. GHIRLANDA, Il diritto della Chiesa. Mistero de comunione, San Paolo, Milán ${ }^{2} 1990,100$; cfr. M. Á. Torres-Dulce, Cánones y leyes de la Iglesia. Nociones fundamentales, Palabra, Madrid 2017, 78.

${ }^{6}$ Cfr. A. Dernburg, Pandette. Volume $1^{\circ}$. Parte $1^{a}$. Parte Generale, Fratelli Bocca, Torino 1906, 155; cfr. A. BURDESE, Manuale di diritto privato romano, UTET, Torino ${ }^{4} 1993,142-143$; cfr. E. BESTA, Le persone nella storia del diritto italiano, CEDAM, Pádova 1931, 124; cfr. M. ROBERTI, Svolgimento storico del diritto privato in Italia. I, CEDAM, Pádova ${ }^{2} 1935$, 145; cfr. M. MARRONE, Manuale di diritto privato romano, Giappichelli, Torino 2004, 164.

7 Cfr. F. de A. Sancho Rebullida, Estudios de Derecho civil II, Eunsa, Pamplona 1978, 47.

${ }^{8}$ Se encuentra en Tafaro la siguiente afirmación: «Può dirsi che nel corso del Principato si arrivò a delineare una nozione confrontabile con il nostro concetto de capacità di agire: la quale era espressa dicendo che il ragazzo diveniva pubes o che la ragazza diventava viripotens», S. TAFARO, Pubes et viripotens nella esperienza giuridica romana, Cacucci, Bari 1988, 22. 
para los germánicos la capacidad de portar armas ${ }^{9}$ ¿ ¿Cuál era el mayor inconveniente de estos criterios? Que exigía la comprobación caso por caso.

La prueba en cada persona de la pubertad era un sistema insostenible en un Imperio con una creciente presencia del Derecho. Fue entonces cuando, los jurisconsultos, por primera vez en la historia del Derecho romano y después de un largo proceso, optaron por apartarse de esa comprobación de la pubertad caso por caso ${ }^{10}$, y sustituirla por la edad ${ }^{11}$. Es decir, la edad en la que normalmente se tenía la capacidad natural según la inspectio corporis, ahora se convertirá en una edad legal que presume la existencia de la capacidad natural y, de este modo, los 12/14 años determinan el inicio de la capacidad de obrar legal ${ }^{12}$. Este punto de llegada aparece tras una larga discusión entre proculeyanos y sabinianos, cuya disputa ilumina la naturaleza jurídica de la $\operatorname{edad}^{13}$.

Esta genialidad inunda el Derecho de los países civilizados ${ }^{14}$, y hasta tal punto está integrado en la mente jurídica actual que nos resulta difícil pensar que pueda existir otro criterio jurídico de determinación de la capacidad na-

9 Cfr. E. Besta, Le persone nella storia..., cit., 119. Los pueblos germánicos fijaron la capacidad también en primer lugar por aspectos externos, aunque más adelante adoptaron el criterio de la pubertad de los romanos, cfr. R. TRIFONE, Le persone e le classi sociali nella storia del diritto italiano, Nicola Jovene, Napoli ${ }^{2} 1933,53-54,57$.

${ }^{10}$ Cfr. E. Besta, Le persone nella storia..., cit., 116; cfr. A. BuRdESE, «Età. a) Diritto romano», en C. Mortati - S. Pugliatti (dirs.), Enciclopedia del Diritto, XVI, Giuffrè, Varese 1967, 79.

11 Así expone Burdese este avance jurídico: «La capacità intellettuale della persona è presupposto per il riconoscimento della capacità di agire, è, a sua volta, condizionata anzitutto al raggiungimento di una determinata età. La giurisprudenza romana è tuttavia orientata, sin da antico, all'accertamento, caso per caso, dello sviluppo, vuoi fisico vuoi psichico, dell'individuo, al fine di riconoscergli una totale o parziale capacità intellettuale, e, quindi, di agire, mentre solo progressivamente si viene a sostituire siffatto accertamento con la determinazione di limiti generali di età», A. BuRDESE, Manuale di diritto..., cit., 139; cfr. E. BESTA, Le persone nella storia..., cit., 115; S. TAFaro, Pubes et viripotens..., cit., 95.

12 Cfr. B. Albanese, Le persone nel diritto privato romano, Tipografía S. Montaina, Palermo 1979, 431; cfr. A. Burdese, Manuale di diritto..., cit., 140; cfr. S. TAFARO, Pubes et viripotens..., cit., 2122. En estos autores se pueden ver fuentes romanas refiriéndose a la pubertad establecida por la edad como plena capacidad de obrar. Cfr. K. L. ARnDTs, Le Pandette. Volumen I. Parte Prima, Fava e Garagnani, Bologna 1882, 124; cfr. J. Delmaille, «Age», en R. NAZ (dir.), Dictionaire de Droit Canonique, I, Librairie Letouzey et Ane, París 1935, 342, sobre la pubertad legal y la pubertad natural (discusión que la moderna doctrina continúa entre capacidad de obrar legal y capacidad natural, o entre edad legal o edad natural).

13 Cfr. R. Trifone, Le persone e le classi..., cit., 51; cfr. M. Marrone, Manuale di diritto..., cit., 164; cfr. V. Arangio-RuiZ, Istituzioni di diritto romano, Eugenio Jovene, Napoli ${ }^{40} 1978$, 493; cfr. P. Bonfante, Instituciones de Derecho Romano, Reus, Madrid '52002, 56.

${ }^{14}$ Cfr. M. Planiol, Traité Pratique de Droit Civil Français. Tome I. Les persones, Libraire générale de droit et de jurisprudence, Paris 1925, 307. 
tural al margen de la edad ${ }^{15}$. Surgió como un avance en el Derecho, que se aplicó en todos los ámbitos, y así lo asumió la Iglesia ${ }^{16}$.

Un dato interesa resaltar: la edad no es nunca una limitación de la capacidad natural, sino una especificación de la misma ${ }^{17}$. La edad es el criterio que el Derecho ha individualizado para concretar y medir la capacidad natural con la que se identifica como paso previo a la determinación legal de la capacidad de obrar, sustituyendo la comprobación de la capacidad natural caso por caso a que conducían los anteriores criterios. Se establecía así una sustitución técnica del hecho presunto -capacidad natural- por el hecho base -edad naturalapoyados en la experiencia de que a determinada edad la mayor parte de las personas solían tener determinada capacidad ${ }^{18}$.

Es al manejar estos conceptos donde tiene lugar, a mi modo de ver, una imprecisión frecuente en la actualidad: confundir las pruebas de la capacidad natural con la misma capacidad natural. Si en los pueblos germánicos inicialmente se miraba a la capacidad de portar armas, ello no significaba que la ca-

15 Cfr. F. De Castro y Bravo, Derecho civil..., cit., 150.

${ }^{16}$ De los trabajos de preparación del CIC de 1983: «Codex I. C. primo quidem legislationem propie canonicam de aetatibus, sicut de statu mentis et de sexu, stabilivit. Ius Decretalium non habebat de iisdem praescripta, et in genere ad capacitatem personarum admisit et applicavit praescripta quae in iure romano vigebant. Unde iuris canonici antique monumenta pauca tantum de iisdem habuerunt praescripta, sed universa doctrina ante Codicem applicavit quae ius romanum de hac materia praescripta edixit», Communicationes 21 (1989) 36. Con anterioridad ya lo apuntaba Gasparri: «Ecclesia hanc legislationem adoptavit (sobre la pubertad legal de Justiniano), eamque ipse Codex recepit, ut patet ex can. 88.2. Equidem in cit. c. 3, X, De Desponsatione impuberum, IV, 2», P. GaSPARRI, Tractatus canonicus de matrimonio. Volumen I-II, Typis Polyglottis Vaticanis, Vaticano 1932, 290; cfr. G. Michiels, Principia Generalia..., cit., 37; cfr. M. ConTe a Coronata, Institutiones iuris canonici. De sacramentis. Tractatus canonicus. Volumen III, Marietti, Casali ${ }^{3}$ 1957, 359; cfr. F. X. WERNZ - P. VIDAL, Ius canonicum. Tomo V. Ius matrimoniale, Universitatis Gregorianae, Romae 1925, 227; cfr. A. VeERMEERsCH - J. Creusen, Epitome iuris canonici. Tomus II, Mechlinlae, Bruxelles ${ }^{6} 1940,236$; cfr. J. Mans Puigarnau, Derecho matrimonial canónico. Volumen I, Bosch, Barcelona 1959, 152; cfr. E. MONTERO Y GuTIÉRREZ, El matrimonio y las causas matrimoniales, Sáez, Madrid ${ }^{7} 1965,120$; cfr. E. F. REgaTillo, Derecho matrimonial eclesiástico, Sal Terrae, Santander 1962, 132. Esa asunción recorre la historia de los avances seculares que se van incorporando a la ciencia canónica. Las aportaciones de la pandectística fueron prudentemente asumidas en la gran obra de Wernz poco antes de la primera codificación canónica tal y como hace notar Lombardía, cfr. P. Lombardía, Escritos de Derecho canónico I, Eunsa, Pamplona 1973, 455.

${ }^{17}$ Stanzione insiste en esta idea: «Non solleva dubbi, infatti, l'affermazione che l'età si presenta come unità di misura, come trasposizione nel linguaggio chiaro delle cifre di un fenomeno altrimenti indefinibile», P. STANZIONE, Capacità e minore età..., cit., 262.

18 A este aspecto se refiere Savigny en la siguiente cita: «I sabiniani volevano soltanto andar più sicuri, cercando per quanto era possibile di sostituire mediante indagini la certezza alla presunzione, che anch'essi non ponevano in dubbio», F. C. Di SAVIGNY, Sistema de Diritto..., cit., 82; también en cfr. R. AsTOLFI, Il matrimonio nel Diritto romano preclassico, CEDAM, Padova 22002, 91. 
pacidad natural para el Derecho germánico fuera la aptitud física, sino que ésta era una prueba de la capacidad natural (psíquica fundamentalmente), esto es, un criterio visible y comprobable para llevar a cabo la atribución de capacidad de obrar legal. Lo mismo ocurre en el Derecho romano: la capacidad de engendrar era la prueba de la capacidad natural y por lo tanto la base para la atribución de la capacidad de obrar legal; pero en ningún caso la capacidad para engendrar fue en sí misma la capacidad de obrar legal. Como la capacidad de engendrar acontecía a una edad determinada generalmente, a esa edad se le llamó pubertad legal. Ésta es siempre una edad legal que vendrá referida a las capacidades cognitivas, volitivas y corporales como base para atribuir la plena capacidad de obrar ${ }^{19}$.

La edad de la pubertad legal no podía referirse sólo a la capacidad de generar porque era la mayoría de edad para todos los contratos, que venía escenificada por el cambio a la toga virilis y la entrada en el foro, lugar de la vida pública romana ${ }^{20}$. Más claro se ve en el caso del sui iuris sometido a la tutela, que alcanzaba la plena capacidad de obrar al llegar a la pubertad legal. Se confundía la prueba (corporal) de la capacidad natural con la misma capacidad natural (psicológica, fundamentalmente) ${ }^{21}$. Este error en el ámbito canónicomatrimonial producirá una gran desorientación doctrinal en el siglo XX que oscurecerá, junto a otras causas, la naturaleza jurídica de la edad matrimonial. La capacidad de obrar matrimonial fue siempre la pubertad legal, y el Derecho canónico nunca la ha reducido a la sola potentia coeundi.

En consecuencia, la doctrina, de forma unánime, hace depender la capacidad de obrar de la capacidad natural expresada en la edad (de forma positi-

19 «La pubertas è la più antica del pari che la più importante (...). Da tal momento in poi esso è pienamente capace di agire. (...)», F. C. Di SAVIGNY, Sistema de Diritto..., cit., 25-26, 65; cfr. A. Dernburg, Pandette..., cit., 145; cfr. S. Tafaro, Pubes et viripotens..., cit., 22; cfr. B. AlbaneSE, Le persone nel diritto..., cit., 431; cfr. A. BURDESE, Manuale di diritto..., cit., 140; cfr. P. BoNFANTE, Instituciones de Derecho..., cit., 56; cfr. A. RavÀ, Istituzioni di diritto privato. II. Diritto delle persone, CEDAM, Padova ${ }^{5} 1932,49$; cfr. R. TRIFONE, Le persone e le classi..., cit., 61; cfr. R. AsTOLFI, Il matrimonio nel Diritto romano classico, CEDAM, Padova 2006, 234; cfr. R. DE RUGGIERO, Istitutioni di diritto..., cit., 267.

${ }^{20}$ Cfr. M. RoberTi, Svolgimento storico..., cit., 140. El concepto de enfermedad lo tomo en sentido amplio como 'la ausencia de la normal capacidad'.

${ }^{21}$ Por ejemplo en cfr. F. DEgnI, Le persone fisiche e i diritti della personalità, en F. VASSALLi (dir.), Trattato di diritto civile italiano II-I, UTET, Torino 1939, 274-275. En todo caso reconoce que con el tiempo se añadió también como base de la edad la propiedad psíquica, y que es el criterio que llega a la codificación; igualmente en cfr. M. ROBERTI, Svolgimento storico..., cit., 138; cfr. S. TAFAro, Pubes et viripotens..., cit., 221-222. 
va), o de su ausencia manifestada en la enfermedad ${ }^{22}$. Que la capacidad natural se identifique por estos dos elementos revela el carácter realista de la teoría de la capacidad de obrar: interesa la capacidad verdadera, real, histórica, de una persona determinada. Algunos autores dan un paso más al considerar a la misma persona en la edad, no sólo en su dimensión psíquica, sino en las circunstancias espacio-temporales que determinan esa aptitud ${ }^{23}$.

Pero una vez que la edad y la enfermedad han sido individualizadas como elementos que concretan y señalan la capacidad natural, es oportuna otra cuestión: ¿cómo se articula jurídicamente esa capacidad natural?, ¿cómo se convierte en capacidad de obrar legal? Aquí la doctrina sigue siendo unánime: por medio de la edad legal y de la incapacidad declarada judicialmente. La edad legal se basa en la edad natural, y la incapacidad en la enfermedad.

Recapitulando, los elementos que resultan son éstos: 1) capacidad de obrar legal: edad legal e incapacidad declarada por el juez; y 2) capacidad natural: edad natural y enfermedad. Y como es frecuente en la teoría de la persona y de la capacidad, aparece lo natural y lo jurídico, por lo que la pregunta obligada es la siguiente: ¿cómo se relacionan la capacidad de obrar legal y la capacidad natural? Éste es el punctum dolens en el que la doctrina mantiene un intenso debate aún no concluso, teniendo a la capacidad de los menores como centro de la investigación.

\section{Modelos Jurídico-realistas DE LA CAPACIDAD DE ObRAR}

La doctrina, desde la pandectística alemana, ha conseguido individualizar el concepto de la capacidad de obrar señalando su esencia: "la capacidad natural" (o "el ejercicio por sí mismo", o "gobierno de sí mismo", o "uso de razón", etc.). En un momento posterior ha concretado esa capacidad natural por medio de la edad y la enfermedad. El siguiente paso es articular desde la técnica jurídica la capacidad natural (edad natural y enfermedad) y la capaci-

${ }^{22}$ Así sintetiza De Castro este binomio habitual en la doctrina: «El capaz para todos los actos de la vida civil es quien reúne estas dos notas: la positiva de estar emancipado sin restricciones y la negativa de no estar incapacitado», F. DE CASTRO y BRAVO, Derecho civil..., cit., 54.

23 «Anche a voler designare l'età come un aspetto della persona -più correttamente, espressione numerica di uno stadio del suo sviluppo fisio-psichico-, essa costituirebbe sempre parte integrante della realtà unitaria in cui consiste l'uomo», P. STANZIONE, Capacità e minore età..., cit., 262-263. También Carnelutti: «La edad constituye un modo de ser de la persona», cfr. F. CARNELUTTI, Teoría general del Derecho, Revista de Derecho privado, Madrid 1941, 244. 
dad de obrar legal (edad legal e incapacitación) ${ }^{24}$. En este punto los autores se dividen.

A mi modo de ver, tres son los modelos de articular entre sí la capacidad de obrar legal y la capacidad natural que se distinguen en la doctrina. Uno sería el modelo positivista, que mantiene la negación de toda relevancia jurídica a la capacidad natural cuando no está prevista en la capacidad de obrar legal. Otro sería el modelo naturalista, que postula un reconocimiento directo y progresivo de la capacidad natural y la negación de cualquier capacidad de obrar legal establecida por medio de una edad. El primero logra la seguridad jurídica en contra de la realidad, y el segundo gana en justicia en contra de la viabilidad jurídica. Estos dos sistemas son extraños en la doctrina, y sólo aparecen como tendencia en algunas propuestas.

El tercer modelo es el jurídico-realista, en el que se encuentra la doctrina mayoritaria. Aquí se afirma la relevancia de la capacidad natural y de la capacidad de obrar legal y una cierta conexión entre la realidad y el Derecho, aunque las explicaciones que dan son variadas pero no contrapuestas en el planteamiento: unos señalan que la capacidad natural es el sustrato o presupuesto o fundamento de la capacidad de obrar ${ }^{25}$; otros afirman que la capacidad de obrar tiene

${ }^{24} \mathrm{El}$ problema de fondo se percibe bien en el siguiente texto de Falzea: «Se la capacità di intendere e di volere è il presupposto della capacità di agire -e per conseguenza, la incapacità di intendere e di volere la causa (sia pure mediata) della incapacità di agire-, deve necessariamente escludersi che essa costituisca il substrato di fatto della corrispondente qualità giuridica. Questa precisazione, che ha carattere essenzialmente teorico, appare indispensabile di fronte all'idea, peraltro frequente, secondo cui la capacità di agire (nel diritto penale: la imputabilità) sarebbe un fenomeno complesso, costituito da un elemento di fatto, rappresentato dalla capacità di intendere e di volere, e da un elemento giuridico, costituito dalla corrispondente qualità giuridica», A. Falzea, Capacitá. Teoria generale..., cit., 41.

${ }^{25}$ La doctrina, en el momento de examinar la relación de la capacidad natural con la capacidad de obrar, suele referirse a la primera como el sustratum o presupuesto de la segunda. A la pregunta, de qué significa presupuesto, la respuesta sería, que no cabe ninguna limitación de la capacidad de obrar que no estuviera basada en la capacidad natural, y también, que allí donde hay capacidad natural, debe haber capacidad de obrar. En el fondo se trata de buscar el equilibrio entre la seguridad jurídica y la verdad material. Esta postura es frecuente en la explicación de los autores, cfr. C. MARTíNEZ DE AGUIRRE y ALDAZ, La protección jurídico-civil de la persona por razón de la menor edad (Una aproximación teleológica a las instituciones de asistencia y protección de menores en nuestro Derecho civil), Anuario de Derecho Civil 45 (1992) 1402; cfr. J. L. LaCruZ BERDEJO J. Delgado Echeverría, Elementos de Derecho..., cit., 4; cfr. F. CARnelutti, Notas sobre la capacidad..., cit., 950; cfr. F. FERRARA, Trattato di diritto..., cit., 459; cfr. P. RESCIGNO, «Capacità di agire», en A. AZARA - E. EUla, Novissimo Digesto Italiano, II, UTET, Torino ${ }^{3} 1957,861$; cfr. F. MESSINEO, Manuale di diritto civile e commerciale, Giuffrè, Milano ${ }^{9} 1957,227-228$; cfr. C. RUPERTO, «Età. c) Diritto privato», en C. Mortati - S. Pugliatti (dirs.), Enciclopedia del Diritto, XVI, Giuffrè, Varese 1967, 89. 
una doble dimensión legal y natural a la vez ${ }^{26}$, que es una suma cumulativa de $\operatorname{ambas}^{27}$; $y$ algunos autores catalogan los elementos de la capacidad natural como requisitos o limitaciones de la capacidad de obrar legal -dándole así un carácter negativo- ${ }^{28}$. En todos los casos se establece una relación de causalidad entre la capacidad natural y la capacidad de obrar legal, ofreciéndose soluciones doctrinales que procuran superar la dicotomía y lograr un sistema unitario.

A partir de aquí, y admitida la conexión, la cuestión es la siguiente: ¿con qué técnica articula el legislador la capacidad de obrar legal y la capacidad natural? Desde Justiniano esto se hace por medio de la edad ${ }^{29}$ : se convierte la edad natural en edad legal. Pero el problema es que la edad natural cambia cada día; por ello la doctrina se sigue preguntando: ¿cuántas edades legales se reconocen? Existen varias soluciones técnicas dentro del modelo jurídicorealista para estructurar legalmente la edad y que paso a examinar.

\subsection{Articulación casuística}

La articulación casuística sostiene una equiparación entre capacidad natural y capacidad de obrar, pero intentando dar respuestas a la inseguridad jurídica que generaría ${ }^{30}$. Las posturas más extremas estarían en el modelo natu-

${ }^{26}$ Cfr. M. Dogliotti, Le persone fisiche, en P. Rescigno, Trattato di diritto privato 2. Persone e famiglia. Tomo primo, UTET, Torino 1982, 16; cfr. Q. M. SCAEvOLA, Código civil comentado y concordado extensamente. Tomo I, Moreno y Rojas, Madrid 1889, 148; cfr. E. Ramos Chaparro, La persona y su capacidad civil, Tecnos, Madrid 1995, 283-284, 305; cfr. G. ALPA - G. RESTA, Le persone e la familia. I. Le persone fisiche e i diritti della personalità, UTET, Torino 2006, 25; cfr. N. CoVIELLO, Doctrina general del Derecho civil, Uteha, Mexico D. F. ${ }^{4} 1949,160$.

27 Cfr. J. L. Lacruz Berdejo - J. Delgado Echeverría, Elementos de Derecho..., cit., 4; cfr. A. De Lama Aymá, La protección de los derechos de la personalidad del menor de edad, Tirant lo Blanc, Valencia 2006, 102; cfr. A. Colin - H. CAPITANT, Curso elemental de Derecho civil. Tomo primero, Reus, Madrid 1922, 170, 218; cfr. P. STANZIOne, Persona fisica. Diritto civile, en G. AUTORINo Stanzione - P. StanzIOne, Diritto civile e situazioni esistenziale, Giappichelli, Torino 1997, 94; cfr. IDEM, Capacità e minore età..., cit., 269; cfr. I. RaveTLlat BALLESTÉ, ¿Por qué dieciocho años? La mayoría de edad civil en el ordenamiento jurídico civil español, Anales de la Cátedra de Francisco Suárez 49 (2015) 132.

28 Cfr. C. Gangi, Persone fisiche..., cit., 73; cfr. M. del C. Gete Alonso y Calera, La nueva normativa en materia de capacidad de obrar de la persona, Civitas, Madrid 1985, 25; cfr. F. CARNELUTTI, Teoría general..., cit., 248; cfr. P. STANZIONE, Capacità e minore età..., cit., 207.

29 Cfr. E. BESTA, Le persone nella storia..., cit., 120; cfr. M. MARRONE, Manuale di diritto..., cit., 164.

${ }^{30}$ Sobre ello llama la atención Martínez de Aguirre: «Llevada a su extremo, la correspondencia entre capacidad natural y la capacidad de obrar (que sería un mero reflejo jurídico de aquélla) obligaría a comprobar caso por caso la capacidad natural de las personas, para poder determinar así, también caso por caso, su concreta capacidad de obrar; lo cual es impracticable porque, evidentemente, paralizaría por completo la vida jurídica», C. MARTÍNEZ DE AGUIRRE Y ALDAZ, La protección jurídico-civil..., cit., 1406. 
ralista. A la imposibilidad de un reconocimiento absoluto de la capacidad natural de cada persona se refiere Rescigno: «l'adeguamento della capacità di agire all'attitudine naturale alla cura dei propri interessi non può realizzarsi in modo assoluto ${ }^{31}$. En la actualidad, a causa de la difusa regulación de la capacidad de obrar de los menores, y del hastío de un sistema de capacidad de obrar legal entendido al modo formalista, existe una corriente que se extiende a todo el ámbito de la actuación civil, que postula un reconocimiento legal de la capacidad progresiva y gradual de los menores ${ }^{32}$, lo que en mi opinión es un retroceso técnico y una causa importante de inseguridad jurídica.

Esta corriente propone el establecimiento de varios tramos de edades legales, de modo similar a como ocurría en el Derecho de la Edad Media y en el momento previo a la codificación ${ }^{33}$. Se desecha en consecuencia que haya una edad legal central que establezca con carácter general la capacidad de obrar $^{34}$. La articulación casuística haría más ajustado el sistema de capacidad de obrar, pero al final no consigue superar el positivismo jurídico que a toda costa quiere evitar: ¿no se justifica en esta articulación la validez de los actos mediante la edad legal por muy escalonada que esté en tramos? No consigue dar entrada a la capacidad natural en los ordenamientos, y la pregunta sigue en el aire: ¿es posible que la in/capacidad natural tenga relevancia jurídica sin necesidad de ser codificada como en el Código civil italiano? ${ }^{35}$

${ }^{31}$ P. Rescigno, Capacità di agire..., cit., 862; también en cfr. J. Puig Brutau - L. Puig Ferriol, Fundamentos de Derecho civil. Tomo I. Volumen I. Parte General. Sujeto y objeto del Derecho, Bosch, Barcelona 1979, 277.

32 Sobre esto mismo llama la atención Lete del Río: «Este criterio [fijar una edad como punto de referencia] se está olvidando en las modernas leyes reformadoras del Código civil, que se inclinan por una dependencia entre capacidad y aptitud 'concreta' de la persona que se trate, prescindiendo del dato objetivo de la edad», J. M. LETE DEL Río, Título XI. De la mayor edad y de la emancipación, en M. AlBADALEJO (dir.), Comentarios al Código civil y compilaciones forales, IV, Edersa, Madrid ${ }^{2} 1985,495$.

33 Cfr. G. SCIASCIA, «Capacità giuridica. Diritto romano», en A. AZARA - E. Eula, Novissimo Digesto Italiano, II, UTET, Torino ${ }^{3} 1957,871$. Stanzione propone el establecimiento de varias hipótesis de actuación del menor en vez de edades; el sistema que puede resultar es complicado y seguramente inviable, cfr. P. STANZIONE, Capacità e minore età..., cit., 374-378; cfr. IDEM, Persona fisica..., cit., 242.

${ }^{34}$ Cfr. IDEM, Capacità e minore età..., cit., 315; cfr. E. RAMos Chaparro, La persona y su capacidad..., cit., 301; cfr. A. Nieto Alonso, Capacidad del menor de edad en el ordenamineto patrimonial civil y alcance de la intervención de sus representantes legales, Revista de Derecho civil 3 (2016) 41, en http:// nreg.es/ojs/index.php/RDC.

35 Se hace referencia al artículo 428 del Código civil italiano. Esta norma trataba de responder al necesario recurso que la jurisdicción civil italiana hacía a la incapacidad natural, lo que llevó a algunos autores a exigir una previsión legal. Es una muestra paradigmática del formalismo con el que se afrontó esta cuestión. 


\subsection{Articulación formalista}

La articulación formalista propone el establecimiento de una frontera que separe a las personas en capaces e incapaces atendiendo a su edad: mayores y menores. Esta postura, sin ser la preferida, supone un avance ${ }^{36}$, y es la mayoritaria. En mi opinión, el legislador de los códigos civiles y canónicos, más que preguntarse por una adecuación mimética entre la capacidad de obrar legal y la capacidad natural, planteó la cuestión fundamental de otro modo quizá menos ambicioso pero más práctico: ¿cuál es el mínimo necesario de capacidad natural para ejercer "por sí mismo" el conjunto de los actos de la vida civil o eclesiástica? Ahora no se trata de seguir la capacidad natural en su transcurso vital, sino de fijar el inicio a partir del cual se considera que se tiene esa capacidad mínima o media ${ }^{37}$ para poder llevar a cabo los actos y negocios jurídicos en general. Antes de esa edad no hay capacidad de obrar legal, después sí.

Ciertamente, sería injusta esta estructuración legal tan tajante en tanto que el recién nacido tendría la misma capacidad de obrar que al que le falta un día para la mayoría de edad ${ }^{38}$. Sin embargo el legislador matiza esta división drástica reconociendo algunos ámbitos en los que se establece una edad inferior, y sobre todo mediante la edad intermedia de la emancipación referida en el Derecho moderno a la capacidad de obrar ${ }^{39}$. Es una postura sensata, y las propuestas más exacerbadas estarían en el modelo positivista.

La postura anterior ganaba en justicia por acercarse más a la capacidad natural en su previsión legal, y la actual gana en sencillez y seguridad jurídica reduciendo el cuadro de la capacidad de obrar a la mayoría y minoría de edad -con la edad intermedia de la emancipación- y reconociendo capacidades de

${ }^{36}$ Cfr. F. de A. Sancho Rebullida, Estudios de Derecho..., cit., 89.

37 Cfr. U. Gualazzini, «Età. b) Diritto intermedio», en C. Mortati - S. Pugliatti (dirs.), Enciclopedia del Diritto, XVI, Giuffrè, Varese 1967, 80.

38 Cfr. C. Martínez de Aguirre y Aldaz, La protección jurídico-civil..., cit., 1423; cfr. IDEM, La edad, en P. De Pablo Contreras (coord.), Curso de Derecho civil. Volumen I. Derecho privado. De-

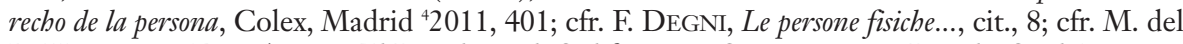
R. Valpuesta Fernández, El Derecho civil. Codificación y Constitución, en Derecho Civil. Parte general. Derecho de la persona, Tirant lo Blanc, Valencia ${ }^{42003,} 213$.

39 Cfr. J. M. Lete del Río, Título XI. De la mayor edad..., cit., 499, 504; cfr. C. MartíneZ de AgUIrRe y Aldaz, sub. 314-324 Cc, en P. De Pablo Contreras - R. Valpuesta Fernández, Código civil comentado, I, Civitas-Thomsom Reuters, Navarra 2011, 1323-1324; cfr. N. PÉREZ DE CASTRO, El menor emancipado, Tecnos, Madrid 1988, 33; cfr. F. FERRARA, Trattato di diritto..., cit., 491-492; cfr. G. GoubEaux, Traité de Droit civil. Les personnes, Librairie générale de Droit et de Jurisprudende, París 1989, 322. 
obrar especiales. Sin embargo, una y otra postura siguen construyendo dos mundos paralelos: el mundo natural (al que tiende la articulación casuística) y el mundo jurídico (al que tiende la articulación formalista). En ambos casos la capacidad natural se cristalizaría al ser estructurada legalmente en el sistema de capacidad de obrar y cualquier desajuste sería considerado un mal menor, hasta el punto que Messineo ha llegado a afirmar: «La maturità di fatto non conta, agli occhi della legge» ${ }^{40}$.

\subsection{Articulación técnico-jurídica}

En el ámbito de la persona física y de la capacidad jurídica se da siempre una tensión entre un mundo jurídico y el mundo real, y que alcanza también a la capacidad de obrar. En mi opinión, ninguna de las posturas anteriores consigue una explicación acabada y cabal del desenvolvimiento del sistema jurídico de capacidad de obrar previsto en los diferentes códigos (civiles y canónicos): ni con la capacidad de obrar legal por tramos, ni con la división entre una mayoría y minoría de edad. El debate es intenso y abarca un gran número de asuntos que esas técnicas no logran resolver, siendo imposible encontrar un criterio común que nos permita comprender y aclarar todos los supuestos de la cuestión.

El empeño de la doctrina se centra en articular la capacidad de obrar legal y la capacidad natural, pero los interrogantes se plantean aisladamente: ¿cómo se mide la capacidad o incapacidad?, ¿la edad se ha de entender como frontera entre la capacidad y la incapacidad de obrar de las personas?; si es así, ¿se ad-

${ }^{40}$ F. Messineo, Manuale di diritto..., cit., 234. Igualmente Rescigno: «Quando il soggetto sia legalmente capace di agire, è irrelevante l'incapacità naturale», P. RESCIGNO, Capacità di agire..., cit., 864. En estos términos se expresa Ondei: «La incapacità di agire è presunta, o, per meglio dire, stabilita dalla legge nel caso della minore età, indipendentemente dalla effettiva capacità mentale che il soggetto possa avere», E. ONDEI, Le persone fisiche e $i$ diritti della personalità, UTET, Torino 1965, 96. Aquí se mantienen paralelas sin coordinarse unitariamente. Igualmente en cfr. B. WindSCHEID, Diritto delle pandette..., cit., 893. En mi opinión lo que existe es una falta de enfoque sobre la naturaleza jurídica de las normas legales que establecen la capacidad de obrar. Por un lado está la capacidad natural y por otro las normas que reconocen la capacidad de obrar legal: el problema es cómo se articulan. Puede parecer que los autores mantienen una posición formalista porque remarcan el enunciado legal en demérito de la capacidad natural, sobre la que se apoya, dicen, mediatamente. Del mismo modo que el sujeto de derecho no se apoya mediatamente en el hombre real, tampoco la capacidad de obrar legal se apoya mediatamente en la capacidad natural. El hombre real y el sujeto de derecho es lo mismo, y la capacidad de obrar legal y la capacidad natural son también lo mismo. A mi juicio, el problema es hallar la técnica que permita armonizar adecuadamente, sin contraponer, la capacidad natural y la capacidad legal en una relación donde se impliquen mutuamente sin excluirse. 
miten excepciones?; ¿estas excepciones han de estar previstas por la ley?; ¿qué valor ocupa la capacidad natural en el ordenamiento?; ¿está 'vigente' de algún modo la capacidad natural?; ¿qué relación existe entre la edad y la incapacidad?; ¿cuál es la capacidad de obrar de los menores?; ¿por qué no son nulos de pleno derecho $^{41}$ los actos o negocios jurídicos llevados a cabo por el menor sin capacidad de obrar legal pero con capacidad natural?; ¿cuál es la responsabilidad no penal de los menores con capacidad natural y sin capacidad de obrar legal?; de admitir el principio de capacidad a los menores con capacidad natural, ¿¿cuál sería su soporte legal para cumplir con las exigencias del principio de legalidad? Estas cuestiones son las que se plantean en el ámbito civil, que en su mayoría se trasladan al ámbito canónico, y que en mi opinión reclaman la pregunta fundamental: ¿cuál es la naturaleza jurídica de la mayoría de edad legal?

Entre la articulación formalista y la casuística, con una cierta tendencia a caer en planteamientos antijurídicos, en el primer caso por romper con el fundamento de la capacidad natural, y en el segundo por renunciar a la técnica jurídica, existe otra articulación que ha sido olvidada. En mi opinión, la capacidad natural no es un simple fundamento o presupuesto de la capacidad de obrar legal ni tampoco está en una relación de mera causalidad, sino que es un elemento de ella, siempre presente en la norma de la capacidad de obrar. No se trata de hacer un reparto de importancia jurídica entre la capacidad de obrar legal y la capacidad natural, sino verlas dentro de un mismo sistema. El problema es que se olvidó la técnica jurídica (ni formalista ni casuística) que permitía una articulación aceptable ${ }^{42}$. Esta técnica es la mayoría de edad legal como presunción iuris tantum de capacidad.

${ }^{41}$ La "no nulidad absoluta" es sinónimo de "anulabilidad", pero he preferido mantener la expresión citada para resaltar uno de sus efectos más importantes como es el mantenimiento de la validez del negocio jurídico hasta que no sea definitivamente atacado por el procedimiento que corresponda en cada caso. Ha sido una cuestión discutida. Pero incluso entre aquellos autores que sostienen que se trata de un contrato sin validez, podrían admitir el efecto de la "no nulidad absoluta". Ésta es, por ejemplo, la postura del Tribunal Supremo español: «En este sentido se ha manifestado nuestra jurisprudencia, manifestando que los contratos celebrados por los menores de edad no son nulos ni inexistentes, sino anulables. Ahora bien, precisa la STS de 28 de abril de 1977 que hay que determinar "si se trata de un menor sin capacidad natural o con ella, y que en el primer caso el contrato será inexistente y en el segundo anulable"», R. LÓPEZ SAN LUIS, La capacidad contractual del menor, Dykinson, Madrid 2001, 157. Además, esta cuestión es solucionada de forma diversa en los códigos civiles de los distintos países.

42 ¿Por qué se olvidó? En mi opinión por los parámetros ideológicos de la codificación. Se identificaba el Derecho con la ley (el Código), y los jueces pasaban a ser la bouche de la loi, lo que desplazaba la jurisprudencia a un apéndice del Derecho y no a una elemento constitutivo. Es normal que esta división drástica entre la ley y su aplicación sembrara una sospecha inicial sobre la 


\section{LA MAYORÍA DE EDAD COMO PRESUNCIÓN DE CAPACIDAD}

El carácter presuntivo de la edad legal es la posición olvidada, la propia de los jurisconsultos romanos, la técnica con que surgió la edad en el Derecho. En efecto, no existe un establecimiento general de la capacidad de obrar legal sin excepciones ni un reconocimiento de la capacidad natural de cada persona. Sí existe en cambio el establecimiento de una presunción jurídica donde la generalidad y el caso concreto son atendidos: la edad establece la regla general, y la excepción es atendida en el caso particular enjuiciado en el proceso judicial. Así surgió la edad en el Derecho y en mi opinión ésta sigue siendo la ratio iuris de las normas sobre la capacidad de obrar en los distintos códigos civiles y canónicos. De este modo se logra el equilibrio entre la seguridad jurídica y la verdad material, entre técnica y justicia.

Por otro lado, el sistema de capacidad de obrar encuentra su comprensión cabal con la consideración conjunta de la regla general (edad legal) y las excepciones (recurso al caso concreto), es decir, atendiendo al momento normativo y al momento procesal del Derecho. De otro modo, se caería en un reduccionismo que llevaría a una interpretación positivista de la edad legal. La naturaleza genuina de la edad legal se capta después de tener en cuenta las excepciones que los ordenamientos prevén en la fase judicial, momento en que la edad legal emerge como presunción iuris tantum de capacidad debido a la prueba en contrario.

Eso hace que la edad legal no encaje en la estructura de una simple norma positiva: si 'A' entonces 'B'; si no 'A' entonces no 'B'. Sino en la de una presunción jurídica: si 'A' entonces ' $\mathrm{B}$ '; si no 'A' entonces ' $\mathrm{B}$ ' si se prueba ' $\mathrm{C}$ '. Donde 'A' es la edad legal, 'B' es la atribución de la capacidad de obrar, y 'C' es la capacidad natural. En efecto, en la edad legal como presunción iuris tantum se permite que se lleve a cabo la atribución de capacidad de obrar en sede judicial a quien no se encuentra en el hecho base (la mayoría de edad), o viceversa. Ésta es la peculiaridad de las normas que establecen una presunción iuris

\footnotetext{
presunción iuris tantum, que permitía dejar si efecto la norma material en el ámbito procesal. También ha influido en el olvido el concepto de Derecho que se tenga. Desde el siglo XVII parece como si existiera el mundo real y el mundo jurídico, y las explicaciones irían encaminadas a fundamentar éste en aquél; más tarde la fundamentación será, no tanto en el mundo natural cuanto en la autoridad del legislador; esta concepción explica la postura formalista. Pero también se puede concebir un único mundo, el real, que puede ser abordado técnicamente, con su método propio, por el Derecho; éste no sería fuente de una realidad jurídica, sino la ordenación justa de la única realidad; el Derecho no es un mundo paralelo, es una ciencia que estudia el único mundo que existe.
} 
tantum, donde el hecho presunto (capacidad natural) siempre prevalece sobre el hecho base (edad), a diferencia de lo que ocurre en el resto de normas, en las que el proceso judicial atribuye el derecho si existe el hecho base, y lo niega en caso contrario. En mi opinión, buena parte de las sombras en materia de capacidad de obrar legal tienen su raíz en haber olvidado esta naturaleza jurídica de la edad legal como presunción iuris tantum, la que tenía inicialmente desde el Derecho romano, la que pervivió a través de la Edad Media y la que se mantiene después de la codificación civil y canónica.

Llegados a este punto, aparecen conectados jurídicamente los dos elementos fundamentales que la doctrina civil y canónica señalaba en la teoría de la capacidad: la edad y la enfermedad (entendida como ausencia de la normal capacidad). Esto permite organizar el régimen de capacidad de obrar como sistema, en tanto que existe una interdependencia técnico-jurídica entre ambos elementos. En este apartado me detendré en la edad legal como presunción iuris tantum de capacidad, y en el siguiente en la prueba en contrario de esa capacidad presumida por la edad legal.

En efecto, según mi parecer, fue un gran avance técnico por parte de los códigos civiles y canónicos señalar claramente el límite a partir del cual se tiene capacidad de obrar por medio de una edad legal: la mayoría de edad. Esta técnica fue detectada por Savigny, que aunque contrario a la codificación, pretendía una sistematización de la capacidad de obrar extrayendo los principios del Derecho romano. Savigny puso de manifisto algo muy importante desde un punto de vista técnico: la existencia de una edad romana con carácter general (la "pubertad legal") ${ }^{43}$, mientras que el resto de edades se reducían a veces a un solo negocio jurídico. Pero Savigny asumió sólo parcialmente la solución de tener una edad de referencia, dejando a un lado la técnica presuntiva con que la edad venía aparejada en el Derecho romano. Por lo tanto, el problema no reside en estructurar el sistema de capacidad de obrar legal por medio de una edad general (antes pubertad legal, ahora mayoría de edad), que en mi opinión es un avance, sino en la interpretación que se hace de ella.

Aunque la codificación civil traía unas exigencias técnicas que dificultaron seguir interpretando conforme a la tradición jurídico-clásica la norma de

${ }^{43}$ El resto de edades eran especiales, y a veces se agotaban en un solo negocio jurídico. La pubertad legal era la única edad general; en concreto era la plena capacidad de obrar que más tarde heredarían los códigos con la mayoría de edad, aunque en una edad más cercana a los 25 años (edad en la que no se podía ejercer la restitutio in integrum). Lo importante no es el quantum, sino la técnica de disponer de una edad general. 
la mayoría de edad, si ésta sigue siendo una presunción jurídica en los códigos, ya no hay capaces o incapaces, sino unos que han de acreditar de algún modo su capacidad (los menores) y otros que no (los mayores); por lo que la pregunta de si existe una regla general de capacidad o incapacidad de obrar del menor carece de sentido, precisamente porque por medio de la presunción se consigue de un modo técnico y complejo que cualquier persona con capacidad natural (hecho presunto) actúe con eficacia jurídica. Además, los autores reconocen una cierta 'vigencia' de la capacidad natural en el funcionamiento del Derecho, y si bien no califican la edad legal como presunción jurídica, si la describen de ese modo ${ }^{44}$ al intentar conjugar todos los elementos que confluyen en la capacidad de obrar tal y como funcionan en cada legislación. Igualmente y por ejemplo, la jurisprudencia española interpreta la mayoría de edad civil (art. $322 \mathrm{Cc}$ ) como presunción iuris tantum ${ }^{45}$.

${ }^{44}$ Cfr. J. Puig Brutau - L. Puig Ferriol, Fundamentos de Derecho..., cit., 278; cfr. M. AlbadaLejo, Derecho civil..., cit., 158; cfr. C. Gangi, Persone fisiche..., cit., 76; cfr. A. Colin - H. CAPITaNT, Curso elemental de Derecho civil. Tomo segundo. Volumen I, Reus, Madrid 1923, 6, 8; cfr. A. LÓPEZ AzCONA, La peculiar situación jurídica del menor aragonés mayor de catorce años, Actualidad Jurídica Iberoamericana 2 (2015) 455; cfr. I. RaveTLlat Ballesté, ¿Por qué dieciocho años?..., cit., 130; cfr. A. FERNÁNDEZ DE BuJán, Capacidad. Discapacidad. Incapacitación. Modificación judicial de la capacidad, Revista Jurídica 23 (2011) 54; cfr. P. Stanzione, Persona fisica..., cit., 243-244; cfr. F. de A. Sancho Rebullida, Estudios de Derecho..., cit., 47-48; cfr. F. Degni, Le persone fisiche..., cit., 8; cfr. C. MARTínez DE AguirRe y Aldaz, La edad..., cit., 399; cfr. IDEM, sub. 314-324 Cc..., cit., 1334; cfr. IDEM, La protección jurídico-civil..., cit., 1407, 1418; cfr. J. M. LeTe del Río, Título XI. De la mayor edad..., cit., 504; cfr. J. Castán Tobeñas, Derecho civil..., cit., 151; cfr. R. LÓPEZ SAN LUIS, La capacidad..., cit., 41-42; cfr. R. BERCOVITZ Y RODRíguez Cano, Derecho de la persona ..., cit., 16; cfr. J. L. LaCruz Berdejo - J. Delgado Echeverría, Elementos de Derecho..., cit., 4; cfr. G. Goubeaux, Traité de Droit..., cit., 321-322. En el ámbito canónico se sigue esta misma inercia: cfr. G. Michiels, Normae Generalis Iuris Canonici, Sant Ioannis Evangelistae, Roma 1949, 357-358; cfr. J. Delmaille, Age..., cit., 315; cfr. A. S. Sánchez GIL, «Presunción», en J. OtaduY - A. Viana - J. SEdano (eds.), Diccionario General de Derecho Canónico, VI, Thomson Reuters Aranzadi, Cizur Menor (Navarra) 2012, 426; cfr. M. Á. Torres-Dulce, Cánones y leyes..., cit., 80; cfr. H. A. AYrINHAC - P. J. LydON, Marriage legislation in the New Code of Canon Law, Benzinger Brothers, New York ${ }^{2} 1952,124$; cfr. J. A. Coriden - T. J. Green - D. E. Heintschel, The Code of Canon Law. A text and commentary, Geoffrey Chapman, London 1985, 72; cfr. A. CoRTÉs, «Edad», en J. OTADUY - A. VIANA - J. Sedano (eds.), Diccionario General de Derecho Canónico, III, Thomson Reuters Aranzadi, Cizur Menor (Navarra) 2012, 524.

45 STS 227 de 18 de marzo de 1988: «Que constituye un principio general e indiscutido de derecho, consagrado por el Código Civil y confirmado por la doctrina de esta Sala, el de que la capacidad de las personas se presume siempre mientras que su incapacidad ha de ser acreditada de modo evidente y completo». Igualmente en las SSTS 461 de 19 de mayo de 1998, 683 de 26 julio de 1999, 1082 de 20 de noviembre de 2002, 926 de 15 de octubre de 2001, 716 de 7 de julio 2004, 6888 de 10 de noviembre de 2005, 282 de 29 de abril de 2009, 322 de 5 de mayo de 2011, 617 de 11 de octubre de 2012, 235 de 29 de abril de 2015, 553 de 14 de octubre de 2015 . 
Pero, ¿qué significa calificar la mayoría de edad como presunción iuris tantum? Que la mayoría de edad no tiene como función establecer la incapacidad de nadie, sino llevar a cabo un desplazamiento de la carga de prueba, permitiendo adecuadamente que cualquier persona pueda actuar con eficacia jurídica en el ámbito civil o eclesiástico siempre que concurra la capacidad natural. Dicho de otro modo, la mayoría de edad como presunción iuris tantum permite la eficacia jurídica de todos los actos y negocios jurídicos realizados con capacidad natural suficiente, con independencia de la edad, y todo ello de un modo viable en los ordenamientos sin poner en peligro la seguridad jurídica.

Esta naturaleza jurídica de la edad ofrece una visión integradora al otro gran elemento de la capacidad natural -la enfermedad (ausencia de la normal capacidad)-, permitiendo construir un sistema unitario de la capacidad de obrar. Si la mayoría de edad es una presunción iuris tantum, ¿cuál es la prueba en contrario? Es la enfermedad que afecta a la capacidad natural y que habrá de ser acreditada en el ámbito judicial para un caso concreto o para una persona determinada ${ }^{46}$.

\section{LA PRUEBA EN CONTRARIO DE LA CAPACIDAD PRESUMIDA POR LA MAYORÍA DE EDAD}

La edad se había incorporado legalmente de un modo sencillo a primera vista: se trataba de convertir la edad natural en edad legal. A partir de aquí había varias soluciones técnicas (por tramos, mayoría-minoría, presunción jurídica) que tratan de conjugar la capacidad de obrar legal y la capacidad natural. En cualquiera de ellas la edad es la regla general, que señala cuál es la capacidad mínima necesaria para actuar por sí mismo.

Pero en la teoría de la capacidad de obrar, además de la edad estaba la enfermedad como circunstancia relevante para la capacidad natural, cuyo tratamiento jurídico también tiene sus raíces en el Derecho romano ${ }^{47}$. La enfermedad tiene carácter excepcional y supone la falta de la capacidad natural

\footnotetext{
${ }^{46}$ Sintéticamente lo afirma Messineo: «La capacità di agire è la regola. L'incapacità di agire, ossia l'inettitudine ad agire -suo termine antitético- è l'eccezione (...). Chi afferma l'incapacità debe darsi carico della relativa prova», F. Messineo, Manuale di diritto..., cit., 228.

47 Para el Derecho romano también la enfermedad era la otra gran circunstancia que afectaba a la capacidad de obrar, cfr. E. BESTA, Le persone nella storia ..., cit., 124; cfr. B. ALBANESE, Le persone nel diritto..., cit., 537 ss.; cfr. A. BURDESE, Manuale di diritto..., cit., 142-143.
} 
normal que es lo verdaderamente decisivo ${ }^{48}$. ¿Cómo se ha articulado legalmente la enfermedad que afecta a la capacidad natural? Por medio de la incapacidad declarada judicialmente. En este caso la solución técnica es más sencilla, porque es más fácil una coincidencia entre capacidad de obrar legal y capacidad natural, debido a que la sentencia se ciñe al caso concreto, donde se examina la capacidad natural de un sujeto determinado.

Me interesa subrayar en este elemento dos notas: la excepcionalidad y la accesoriedad. La enfermedad tiene carácter excepcional, y como tal remite a la regla general de la capacidad establecida por la mayoría de edad, y de este modo la mayoría de edad y la incapacidad declarada judicialmente están lógicamente conectadas. Por lo tanto, ¿cuál es el criterio para incapacitar a una persona? La falta de capacidad natural o autogobierno. Pero, ¿cuánto autogobierno o capacidad natural tiene que faltar? Y aquí es donde hay que seguir acudiendo a la mayoría de edad: se ha de carecer del autogobierno medio que la edad señala, es decir, el que una persona tiene a los 18 años ${ }^{49}$-mayoría de edad en la generalidad de los casos-. Éste es el gran criterio positivo ${ }^{50}$ que el juez tiene para hacer la valoración del caso concreto. Además, la jurisprudencia civil de cada país ha ido estableciendo criterios jurídicos que ayudan a perfilar y llenar de contenido esa capacidad media que presume la mayoría de edad, y que ayudan a enjuiciar la capacidad.

${ }^{48}$ Cfr. F. Carnelutti, Notas sobre la capacidad..., cit., 951; cfr. A. Colin - H. CaPitant, Curso elemental..., cit., 294; cfr. M. Planiol, Traité Pratique..., cit., 302.

49 En el Derecho español se ha pronuciado la DGRN en la importante Resolución de 3 de marzo de 1989: «2. (...) y, por otra parte, el artículo 322 del Código Gvil debe ser valorado en conexión con la técnica del Código Civil de fijar, con ocasión de la regulación de actuaciones jurídicas concretas, la edad requerida para su válida conclusión (vid. artículos 46, 443, 662, 992, 1.246 y 1.263 del Código Civil, y 2 de la Ley de Enjuiciamiento Civil, etc.), lo que permite afirmar que si a partir de los dieciocho años se presupone el grado de madurez suficiente para toda actuación civil (con las excepciones legales que se establezcan), por debajo de esta edad habrá de atenderse a la actuación concreta que se pretenda realizar, cubriendo la falta de previsión expresa por cualquiera de los medios integradores del ordenamiento legal (artículos 1, 3 y 4 del Código Civil), y no por el recurso a una regla general de incapacidad que además no se aviene ni con el debido respeto a la personalidad jurídica del menor de edad». Y la SAP B 566 de 12 de julio de 2016 se expresa como sigue: «Sacramento tiene 63 años, pero no consta que su edad mental sea inferior a la de una persona de 18 años». La cursiva es mía.

50 La perspectiva positiva interesa recuperarla en el ámbito de la capacidad de obrar: «Nella scienza del diritto, l'aspetto negativo dei fenomeni e visto solitamente nell'ottica dell'eccezionalità e ad esso è lecito riservare nelle trattazioni non più di un fugace cenno, mentre l'analisi debe svolgersi sul piano delle connotazioni positive, rispettando ed allienandosi così a ciò che avviene normalmente: la valutazione del profilo patologico non assurge a livello, non rispecchierebbe adeguatamente la realtà», P. STANZIONE, Capacità e minore età..., cit., 192. 
Además, existe la nota de la accesoriedad, manifiestada en que la incapacidad declarada judicialmente es una regulación jurídica dependiente de la edad, un elemento que viene a completar el sistema de la capacidad de obrar cuyo núcleo es precisamente la mayoría de edad entendida como presunción jurídica. Es más, la incapacidad declarada judicialmente es la pieza última en el cuadro legal de la capacidad de obrar, sin la cual no sería posible una comprensión completa y unitaria de ésta. Ello obliga a que la capacidad natural -el ejercicio por sí mismo, el autogobierno o uso de razón- sea el mismo y único punto de referencia tanto de la mayoría de edad (para presumir su existencia a unos años determinados, normalmente 18 en la mayoría de los códigos) como de la incapacitación (para destruir esa presunción), tal y como la doctrina reconoce unánimemente, pero teniendo en cuenta que la misión de la mayoría de edad es ofrecer una 'capacidad natural cuantificada' que actúa de marco legal en la fase judicial.

Es decir, si consideramos globalmente ambos elementos (mayoría de edad e incapacitación), estaremos en condiciones de calificar adecuadamente la naturaleza jurídica de la mayoría de edad como presunción iuris tantum de capacidad y de hallar así la comprensión de la capacidad de obrar como sistema. La incapacidad declarada judicialmente no es sino la prueba en contrario; ésta puede ser estable si la enfermedad es persistente, y a ella se refiere la incapacitación judicial; o puede ser puntual si la afectación de la capacidad natural no es habitual, y a ella se refiere la anulación por sentencia de los actos concretos llevados a cabo con incapacidad natural.

$\mathrm{Al}$ igual que ocurría con la edad, la doctrina normalmente no designa la incapacitación como prueba estable en contra de la mayoría de edad, pero sí la describe fenomenológicamente como presunción de incapacidad ${ }^{51}$. Como ni en la edad ni aquí se trata de una calificación técnica sino sólo descriptiva por parte de los autores, el significado al que apuntan es que la falta de capacidad natural es "persistente" -tal y como ha de quedar acreditado en la sentencia-, de modo que la prueba en contra de la existencia de capacidad natural es estable, es decir, igualmente "persistente".

Respecto a la incapacidad puntual que sólo afecta a un acto, la solución se dirige a un examen particular en sede judicial, ahora no sobre la capacidad

${ }^{51}$ Cfr. I. Tena Piazuelo, La capacidad para realizar actos con eficacia jurídica, en la jurisprudencia, en S. De Salas Murillo (coord.), Hacia una visión global de los mecanismos jurídico-privados de protección en materia de discapacidad, El Justicia de Aragón, Zaragoza 2010, 145; cfr. A. ColiN H. CAPITANT, Curso elemental..., cit., 302. 
natural global del sujeto, sino respecto a un acto específico, con la finalidad de declarar su nulidad o validez (dependiendo si tenía o no capacidad natural el sujeto). En este punto la doctrina es mayoritaria al aceptar la capacidad natural como parte del negocio jurídico, y en este sentido dentro del ordenamiento ${ }^{52}$. A la vista de esto, la solución que propongo -la mayoría de edad como presunción iuris tantum - supondría un respaldo legal a la vigencia de la capacidad natural de la persona en la Parte general de los códigos civiles y canónicos, logrando con ello superar la interpretación positivista frecuente en el ámbito civil. Más aún, si bien es cierto que la capacidad natural es un elemento del acto o negocio jurídico, la mayoría de edad legal vendría a responder a la pregunta sobre el quantum de capacidad necesario para los actos en general. Además, desde un punto de vista sistemático, realista y personalista, sería deseable que se diera una respuesta completa desde el Derecho de la persona a la capacidad de obrar cuyos principios y funcionamiento encontraran en la teoría del acto o negocio jurídico y en la Parte especial su aplicación, y no su excepción.

El esquema teórico de la capacidad de obrar descrito tiene su correspondencia en las normas canónicas, cuya interpretación adecuada, en mi opinión, requiere concebirlas como un sistema organizado en torno a la mayoría de edad como presunción iuris tantum de capacidad. El cuadro legal de la capacidad de obrar previsto en las Normas generales del Código de Derecho canónico de 1983 sería el siguiente:

1) Regla general: la norma de la edad legal aplicable a todos (cc. 97-98 CIC).

2) Excepción particular: la incapacidad declarada judicialmente en el caso concreto (c. 99 CIC).

Y retomando una de las cuestiones iniciales, ¿dónde sustentar legalmente la afirmación de la capacidad de obrar del menor siempre que tenga capacidad natural? En la interpretación de la mayoría de edad (cc. 97 y 98 CIC) como presunción iuris tantum de capacidad, lo cual nos lleva a ver las citadas normas, no con la función de establecer una frontera entre la capacidad (mayores) y la incapacidad de obrar (menores), sino con la de distribuir la carga de la prueba, de tal modo que los mayores no habrán de probar su capacidad

${ }^{52}$ Por ejemplo en el c. $124 \$ 1$ CIC. 
natural por tener a su favor la presunción; mientras que en el caso de los menores, su actuación será eficaz jurídicamente siempre que su capacidad natural quede acreditada de algún modo ${ }^{53}$. El examen pormenorizado de este esquema no haría sino ir corroborando que el funcionamiento jurídico (la norma y su aplicación jurisprudencial) del sistema canónico de capacidad de obrar pivota sobre la mayoría de edad como presunción de capacidad, cuyo desarrollo no me es posible efectuar en este trabajo, ya que además requiere relacionarlo con una legislación civil concreta debido a la remisión importante que en este ámbito hace el Código de Derecho canónico de 1983.

La sistemática canónica refleja la teoría de la persona y de la capacidad: 1) sujeto de derecho (c. 96 CIC); 2) capacidad jurídica (c. 96 CIC); 3) capacidad de obrar (cc. 97-99 CIC). La unidad del sistema de capacidad de obrar donde cada uno de los elementos están adecuadamente conectados, se alcanza al interpretar la mayoría de edad como una presunción iuris tantum de capacidad, técnica que permite una recepción de la teoría de la capacidad de obrar según los principios del realismo jurídico, en tanto que se logra que la capacidad natural sea siempre atendida de un modo viable y seguro jurídicamente. Los interrogantes que veíamos anteriormente en la doctrina sobre la articulación entre la capacidad de obrar legal y la capacidad natural reciben así una solución razonable, a la vez que se logra la continuidad con la tradición clásica donde la edad legal es considerada como una presunción nisi malitia suppleat aetatem.

\section{LA MAYORÍA DE EDAD COMO PRESUNCIÓN IURIS TANTUM DE CAPACIDAD EN SENTIDO TÉCNICO}

En este apartado veremos si la mayoría de edad cumple con los requisitos de la presunción desde un punto de vista técnico. La codificación no ha querido prescindir de la edad para estructurar el sistema jurídico de capacidad. La pregunta pertinente ahora es si tampoco ha prescindido de la técnica jurídica que acompañó a la edad en su origen: la praesumptio iuris. En concreto, estudiaré los elementos (examen analítico) y la naturaleza jurídica (examen conceptual) de la presunción iuris tantum para comprobar su coincidencia con los elementos y naturaleza de la mayoría de edad.

\footnotetext{
${ }^{53}$ Los códigos civiles resuelven de diversas formas esta cuestión, por lo que se habrá de tener en cuenta la regulación específica de cada país.
} 


\subsection{Examen analítico}

Para la doctrina procesalista los elementos que se distinguen en cualquier presunción legal son los siguientes: hecho base, hecho presunto, la conexión entre los hechos basada en la probabilidad, el razonamiento presuntivo y la prueba en contrario (iuris tantum). Al mismo tiempo, los elementos que interfieren en la capacidad de obrar son la edad natural, la capacidad natural, la probabilidad de que a determinada edad existe una capacidad que le es propia, la mayoría de edad legal, y la prueba de la falta de capacidad natural. Lo mostraré más detenidamente.

\subsubsection{Hecho presunto (capacidad natural) y hecho base (edad natural)}

Como vimos al inicio, el primer paso que da la doctrina es fijar el punto de partida: la capacidad natural, que aparece especificada por la edad natural tenida en cuenta por los ordenamientos. La capacidad natural es la esencia del sistema de capacidad de obrar, lo que se busca y se pretende; es el único elemento que existía al principio y que se hallaba con una comprobación caso por caso. Sería el sistema ideal pero no es jurídico ni viable y pertenece a un estadio previo al desarrollo técnico del Derecho. Más en concreto, el hecho presunto $^{54}$ señala la capacidad natural mínima o media para ejercer la mayor parte de los derechos y deberes, pero que en principio es desconocido. Es «aquel hecho que se pretende probar» ${ }^{55}$, y cuya prueba resulta difícil y gravosa por tratarse en parte de hechos internos ${ }^{56}$.

El hecho base es la edad natural computada según las reglas del mismo Código; su prueba resulta más fácil en orden a la certeza, sirviendo así de indicio o signo del hecho presunto; es el soporte de la presunción legal en tanto que es la misma capacidad natural individualizada. La edad es un hecho cierto y verdadero, y de este modo cumple con los requisitos necesarios propios del hecho base para poder configurar una presunción legal ${ }^{57}$.

${ }^{54}$ Es la rei incerta del canon 1584 CIC (antiguo c. 1825).

${ }^{55}$ V. Gimeno Sendra, Proceso civil práctico. Tomo IV, La Ley, Madrid ${ }^{4} 2010,942$.

${ }^{56}$ Cfr. J. CARRERAS, Naturaleza jurídica y tratamiento de las presunciones, Revista jurídica de Catalunya $61(1962) 538$.

${ }^{57}$ Cfr. V. Gimeno Sendra, Proceso civil..., cit., 942. Así se desprende, por ejemplo, del artículo 385.1.1. ${ }^{\circ}$ LEC española: «Tales presunciones [legales] sólo serán admisibles cuando la certeza del hecho indicio del que parte la presunción haya quedado establecida mediante la admisión o prueba». En el mismo sentido el derogado artículo 1249 Cc establecía: «Las presunciones no son admisibles sino cuando el hecho de que han de deducirse esté completamente acreditado». 
La técnica de la presunción sirvió para arbitrar una sustitución de la capacidad natural (hecho presunto) por la edad natural (hecho base) ${ }^{58}$ correlativa a aquella capacidad en la normalidad de los casos; y en tanto que permite prescindir del examen de cada caso como regla general, se obtiene viabilidad en el tráfico jurídico. Ahora bien, es necesario que entre la edad y la capaciad natural exista una relación probable, lo que constituye el siguiente elemento.

\subsubsection{Relación entre los hechos: probabilidad basada en la experiencia}

La relación entre los hechos ${ }^{59}$ no ha de ser necesaria, porque si no sería una prueba directa y no tendría sentido la presunción ${ }^{60}$; es decir, no en todos los casos, ni de forma indubitada se da siempre la capacidad natural mínima para ejercer todos los derechos y deberes al llegar a la edad elegida. Se establece una presunción porque no hay certeza sino verosimilitud, probabilidad ${ }^{61}$. Y ha de ser una relación objetiva -real, extra mental, histórica- ${ }^{62}$, no sólo de razón, y que en nuestro caso es la progresiva adquisición de las facultades humanas intelectivas y volitivas con el pasar de los años. Es el plano fáctico que toma de fundamento el legislador, por lo que la relación entre los hechos no ha de ser demostrada por ninguna de las partes al estar ya recogida en la norma.

La probabilidad es la esencia del razonamiento presuntivo que permite al legislador, apoyándose en criterios de prudencia humana, escoger una edad en

${ }^{58}$ Puede recibir otros nombres en función del contexto doctrinal en el que se mencione: hecho conocido, hecho indiciario, indicio; en el ámbito español se emplea «hecho indicio» (art. 385.1 LEC), «hecho probado o admitido como fundamento de la presunción» (art. 385.2 LEC), «hechos o circunstancias concluyentes» (jurisprudencia: p. e. STS 22 de diciembre de 2004), etc.

59 Es «el enlace que ha de haber entre el hecho que se presume y el hecho probado o admitido que fundamenta la presunción» (art. 385.2 LEC). El canon 1584 CIC lo llama probabilis coniectura (antiguo c. 1825).

${ }^{60}$ STS 300 de 2 marzo 2007 respecto al nexo entre el hecho base y el hecho presunto: «Si bien se encuentra en la esencia de la presunción que el enlace preciso y directo que religa el hecho base con el hecho consecuencia se ajuste a las reglas del criterio humano, no se exige que la deducción sea unívoca, pues de serlo nos encontraríamos ante un supuesto de hechos concluyentes».

${ }^{61}$ Cfr. A. S. SÁNCHEZ GIL, La presunzione di validità dell'atto giuridico nel diritto canonico, Giuffrè, Milano 2006, 35; cfr. P. Álvarez SÁNCheZ de Movellán, La prueba por presunciones. Particular referencia a su aplicación judicial en supuestos de responsabilidad extracontractual, Comares, Granada 2007, 122; cfr. J. Agulló Regla, Presunciones, verdad y normas procesales, Isegoría 35 (2006) 14; cfr. L. RAMPONI, La teoria generales delle presunzioni nell diritto civile italiano, Bocca, Roma 1890, 6; cfr. L. PeÑa GONZALO - T. Ausín DíEZ, La inferencia de hechos presuntos en la argumentación probatoria, Anuario de Fisolofía del Derecho 18 (2001) 96; cfr. L. P. ComogLio, Le prove civili, UTET, Torino $22004,489$.

${ }^{62}$ Cfr. A. M. Lorca Navarrete, Tratado de derecho procesal civil. Parte general. El nuevo proceso civil, Dykinson, Madrid 2000, 779. 
que ni existe una mera posibilidad ni una necesidad. Es lo que se llama la "contingencia" o "derrotabilidad" ${ }^{63}$ de las presunciones, que también se cumple en la mayoría de edad. La probabilidad, se basa en la certeza que se tiene sobre la edad y en la habitual conexión de ésta con la capacidad natural. Para saber el grado de probabilidad ante el que nos encontramos el legislador ha de recurrir a un número significativo de casos, es decir, a la experiencia o al id quod plerumque accedit ${ }^{64}$. Como estamos en un ámbito personalista, considero prudente la postura del legislador, posible gracias a la técnica de la presunción jurídica: no acudir a una edad donde haya una seguridad absoluta sobre la capacidad natural, sino a aquella edad que señale el punto mínimo e inicial de esa capacidad aunque implique un cierto "riesgo" ${ }^{65}$.

Ese riesgo asumido se presenta en dos direcciones: la negación de la capacidad de obrar a los que tienen menos edad y que sin embargo pueden tener capacidad natural, y la atribución de la capacidad de obrar a los que en cambio pueden carecer de la capacidad natural mínima a pesar de tener la mayoría de edad. Estos riesgos son amortiguados al configurarse la edad como presunción legal iuris tantum, en el primer caso porque se permite la "no nulidad absoluta" de los actos o negocios jurídicos concluidos por el menor; y, en el segundo caso, por la prueba en fase judicial de la falta de la capacidad natural presumida por la norma. En el momento de la prueba interesa el hecho presunto, que incialmente había sido sustituido por la edad (hecho base), pero que al entrar en el ámbito del caso concreto se convierte en el criterio fundamental de la decisión del juez.

El elemento de la experiencia, como es el principio de normalidad en la producción de los hechos ${ }^{66}$, ayuda a la configuración de la presunción legal y le permite una conexión con la realidad social ${ }^{67}$. Pero cuando el recurso al caso

${ }^{63}$ Cfr. J. Aguiló Regla, Presunciones, verdad..., cit., 12-13; cfr. L. Peña GonZalo - T. Ausín DíEz, La inferencia de hechos presuntos..., cit., 96.

${ }^{64}$ Cfr. A. M. LorCa NavarreTe, Tratado de derecho procesal..., cit., 778.

65 Cfr. P. Álvarez Sánchez de Movellán, La prueba por presunciones..., cit., 117.

${ }^{66} \mathrm{La}$ capacidad natural está mediada por su realidad social o máxima de experiencia; es decir, las circunstancias sociales pertenecen al interior de la capacidad natural y así lo refleja la norma legal. Se habla también por la doctrina de una adaptación de la regla legal a las circunstancias sociológicas, cfr. C. MARTíNEZ DE AgUtRRE y AlDAZ, La protección jurídico-civil..., cit., 1420. Lasarte apunta otra razón junto a la madurez a la hora de fijar una edad, como es la dependencia con la formación e instrucción de los jóvenes, cfr. C. LASARTE, Parte general y derecho de la persona. Principios de derecho civil, Marcial Pons, Madrid ${ }^{17} 2011,189$.

67 A ello se refiere la teoría de la normalidad (fitting): «la necesidad de que, en el caso concreto, se admita como verdadero aquello que lo es en la mayoría de los casos, mientras que razones no se opongan», J. CARRERAS, Naturaleza jurídica..., cit., 538. 
concreto se generaliza en exceso, es preciso proceder a una reforma legislativa en virtud de la regla id quod plerumque accedit ${ }^{68}$. Éste es el motivo de las reformas en gran parte de los códigos civiles y del cambio del CIC de 1917 al CIC de 1983 sobre la mayoría de edad. En mi opinión, lo mismo ocurre con la elevación de la edad legal matrimonial en dos años para el varón y para la mujer en el CIC de 1917.

Un cambio en la experiencia ha de producir lógicamente un cambio en el razonamiento presuntivo, ya que esta técnica es un modo peculiar de contacto del Derecho con la conducta humana real que pretende regular. El estudio de las dimensiones de la capacidad natural mínima ha de tener en cuenta que se van manifestando en unos individuos concretos que maduran en una sociedad determinada, lo que incide en su progresiva evolución. Esto obliga a la mayoría de edad a considerar las nuevas circunstancias sociales para reflejar verdaderamente la capacidad natural mínima o media y no quedarse obsoleta, incorporando los cambios que vayan introduciendo en ella los factores sociales; es decir, la edad es la presunción de la capacidad natural y sus circunstancias. Pero detectar la influencia de factores externos en las facultades personales psicofísicas no significa sustituir el criterio básico en la determinación de la capacidad de obrar, que siempre ha de ser la capacidad natural mínima, si se quiere respetar el principio personalista de la libertad según el cual el individuo debe poder actuar cuando posee la capacidad adecuada. Pero aquí ya estamos en el ámbito del razonamiento asumido por el legislador: la mayoría de edad legal.

\subsubsection{Razonamiento presuntivo (mayoría de edad legal)}

Este elemento hace que la presunción sea iuris y no bominis. Es el razonamiento lógico realizado por legislador, basado en la probabilidad, que siguiendo la relación entre el término a quo -la edad natural- y el término ad quem -la capacidad natural mínima o media-, saca una consecuencia jurídica ${ }^{69}$ :

${ }^{68}$ Además, ha de haber un nexo que se dé, no siempre y en todos los casos, sino en la mayoría de ellos, y que sea razonable. Se observa, que el legislador al fijar una edad, tiene en cuenta id quod plerumque accidit, es decir, «la consideración de que una persona normal, en condiciones normales, a dicha edad ha adquirido ya la capacidad natural bastante para llevar a cabo la actuación o actuaciones a que el legislador le autoriza $-\mathrm{O}$, si se trata de la edad de la mayoría, para reconocerle con carácter general la capacidad de obrar-», C. MARTínEZ DE AgUIRRE y ALDAZ, La protección jurídico-civil..., cit., 1417.

69 Precisa Ortells Ramos hablando de la presunción, que «la consecuencia jurídica de una norma está vinculada a un supuesto de hecho de difícil o imposible comprobación o, simplemente, no comprobado», M. OrTells Ramos, Derecho procesal civil, Thomson-Aranzadi, Pamplona ${ }^{8} 2008,372$. 
dotar de capacidad de obrar a quien tenga la edad de referencia, es decir, a quien se encuentre en el hecho base (el que tenga la edad natural). El razonamiento presuntivo hecho por el legislador no es otro que la norma, en este caso aquella que establece la mayoría de edad legal ${ }^{70}$. Por lo tanto, quien tenga 18 años (mayoría de edad en numerosos códigos) se presume que tiene la capacidad natural mínima o media para todos los actos o negocios jurídicos con carácter general, porque es probable que la tenga a esa edad concreta, facilitando así el ejercicio de los derechos y deberes. Éste es, en mi opinión, el sentido de los cánones 97 y 98 CIC de 1983 (cc. 88 y 89 CIC de 1917).

La mayoría de edad se refiere al ejercicio de los derechos y de los deberes por quien tiene la mínima capacidad natural requerida, y por ello se debe facilitar y no limitar más allá de lo adecuado ${ }^{71}$. Éste es el motivo que llevó a utilizar la técnica de la presunción legal, a través de la cual el legislador se atenía con probabilidad -más que la mera posibilidad y menos que la certeza total- al momento inicial en que concurre la capacidad natural imprescindible para el ejercicio "por uno mismo" de sus derechos. Como recuerdan Peña y Ausín, «que sea razonable no signfica que [no] sea infalible» ${ }^{72}$, y por eso la presunción iuris tantum incluye un mecanismo de autocorrección probando en sede judicial que en el caso concreto no se da la conexión entre el hecho base y el hecho presunto establecida por la mayoría de edad legal.

La reforma de la mayoría de edad -razonamiento presuntivo del legislador- es el intento de seguir la estela que la experiencia indica como aquella primera edad en que se puede llegar a actuar por sí mismo en la vida civil o eclesiástica. En este sentido, no se trataría tanto de un cambio positivista de la norma cuanto de la capacidad natural que la norma presume, y que reclama un cambio legislativo acorde con el modo de funcionar propio de la edad como presunción jurídica.

70 «La máxima de experiencia queda así embebida en la norma legal, y es un instrumento que, una vez utilizado, deja de tener interés lo mismo para las partes que deben cumplir la norma que para el Juez que la aplique en vía jurisdiccional. A las partes y al Juez les está pues vedado corregir el juicio sobre probabilidad y discernir si la máxima existía o ha sido debidamente utilizada; para ellos no hay más que la decisión del Legislador que ha de ser cumplida y tenida en cuenta sin entrar a juzgar sobre la corrección del juicio que le ha servido de base», J. CARRERAS, Naturaleza jurídica..., cit., 532. Lo que se podrá llevar al proceso es que, o bien no es tal el hecho base-que la edad natural es otra-, o que en ese caso concreto falla la máxima de experiencia, es decir, no existe el hecho presunto.

${ }^{71}$ Canon 18 CIC: «Las leyes que establecen una pena, coartan el libre ejercicio de los derechos, o contienen una excepción a la ley se deben interpretar estrictamente».

72 L. PeÑa GonZalo - T. Ausín DíEz, La inferencia de hechos presuntos..., cit., 110. El [no] de la cita se ha de suprimir en la frase de los autores. 


\subsubsection{Iuris tantum}

La clasificación más importante y que atraviesa toda la historia del Derecho hasta nuestros días es la que distingue entre presunciones iuris et de iure, presunciones iuris tantum, y presunciones hominis (judiciales). Según la doctrina mayoritaria, las auténticas son las presunciones iuris tantum, en tanto que las presunciones iuris et de iure son enteramente de Derecho material y las presunciones judiciales enteramente de Derecho procesal. A ambas les falta algún elemento que impide el juego de la presunción genuina. A las presunciones iuris et de iure les falta la "probabilidad", en tanto que es una decisión fija del legislador, no tienen posibilidad de adaptación a la realidad natural y social, no admiten supuestos contrarios a los específicamente previstos en la norma, y son extrañas en los actuales ordenamientos ${ }^{73}$ al no avenirse bien a la solución más justa por impedir el recurso al caso concreto mediante la prueba en contrario propia de las presunciones iuris tantum. $\mathrm{Y}$ a las presunciones judiciales les falta la "norma" que atribuya algún derecho o capacidad; les falta en definitiva el razonamiento presuntivo del legislador.

Las presunciones iuris tantum, a diferencia del resto, tienen una naturaleza específica: su carácter mixto material-procesal. Es decir, están situadas entre las normas de Derecho material, y a la vez hacen referencia al momento procesal de la prueba, con la oportunidad de dejar sin efecto la norma presuntiva material si fallara en ese caso concreto la conexión entre el hecho base y el hecho presunto ${ }^{74}$. Si se prueba que el hecho presunto es otro distinto al previsto por la mayoría de edad (norma material), entonces la eficacia jurídica seguirá a la capacidad natural probada en la sentencia para un caso concreto.

La mayoría de edad presume la capacidad de obrar para todos los actos de la vida civil o eclesiástica de modo general a los que tengan 18 años (en gran parte de los códigos civiles, y en el Código de Derecho Canónico de 1983). Pero puede ocurrir que falle la conexión en un caso concreto entre el hecho base -edad natural-y el hecho presunto -capacidad natural-, y por eso se per-

\footnotetext{
73 Artículo 385.3 LEC: «Las presunciones establecidas por la ley admitirán la prueba en contrario, salvo en los casos en que aquélla expresamente lo prohíba». El CIC no reproduce el canon 1826 CIC de 1917, que reconocía tanto la presunción iuris tantum como la iuris et de iure: «Contra la presunción simplemente de derecho se admite prueba tanto directa como indirecta; contra la presunción de derecho y por derecho, sólo indirecta, esto es, contra el hecho en que se funda la presunción», que es lo mismo que decir que no admite prueba contra la presunción, sino prueba para saber que no es de aplicación la presunción en el caso.

${ }^{74}$ Cfr. A. Colin - H. Capitant, Curso elemental..., cit., 201.
} 
mite la prueba en contrario. Ésta tiene dos modalidades: 1) De forma puntual, y aquí puede operar en dos direcciones: bien mediante el reconocimiento de la capacidad de obrar a un menor en un acto determinado si resulta que tenía capacidad natural, aunque no esté favorecido por la presunción jurídica de capacidad (el caso de la validez de los actos llevados a cabo por los menores o incapacitados), bien mediante la negación de la capacidad de obrar en un acto concreto a quien tenía la presunción a su favor (el caso del mayor de edad que concluye un negocio jurídico con incapacidad natural); en ambos supuestos, la atribución o negación de la capacidad de obrar, como se trata de un caso concreto, obedece a la presencia o carencia de capacidad natural (hecho presunto) en el acto en cuestión. 2) De forma estable: mediante la modificación judicial de la capacidad (c. 88 \$ 3 CIC de 1917 y c. 99 CIC de 1983). Habrá que entender aquí la remisión hecha al Derecho del país al que pertenece la persona.

Por medio de la mayoría de edad legal como presunción iuris tantum, las expectativas del realismo jurídico se cumplen, ya que cualquier persona puede actuar con eficacia jurídica si tiene la capacidad 'real' adecuada.

\subsection{Examen conceptual}

Es frecuente encontrarse, sobre todo en los estudios de introducción a la ciencia jurídica, con un carácter presuntivo genérico atribuido al Derecho como si fuera parte de su esencia, como un modo de comprenderlo globalmente. Pero en estas afirmaciones, que vienen a indicar que en la construcción jurídica del Derecho se opera como una cierta sustitución de la realidad por la norma, el término presumir está utilizado según el uso corriente, y en modo alguno excluye la existencia de la presunción jurídica en sentido técnico, como un instrumento concreto, que tiene una función jurídica determinada, cuya eficacia puede ser descrita con precisión en el desarrollo de un proceso. Así lo hacen ver los romanistas, donde la presunción no viene a ser una especie de característica transversal que designa un modo de ser del Derecho, sino un contrapeso técnico al principio inquisitivo del nuevo proceso de la cognitio extra ordinem ${ }^{75}$. Examinaré ahora, desde la doctrina procesalista moderna, la específica naturaleza de la presunción iuris tantum con intención de comprobar si la mayoría de edad legal se encuadra en este instrumento técnico.

${ }^{75}$ Cfr. Á. D’Ors, Derecho privado romano, Eunsa, Pamplona ${ }^{102004,} 185$. 
Podemos extraer un dato valioso de la doctrina como punto de partida: las presunciones iuris tantum incluyen una referencia a la prueba ${ }^{76}$. Es precisamente aquí, al delimitar la influencia de la presunción sobre la prueba, donde los autores difieren. En cualquier caso, sirva este primer paso de la doctrina como testimonio del carácter procesal de la norma sustantiva de la mayoría de edad. Esto nos lleva a concluir, de momento, que la posibilidad de acceso al caso concreto -ámbito donde se practica la prueba- forma parte de la técnica de la presunción iuris tantum. Esta primera aportación de los procesalistas está en sintonía con los postulados de la teoría de la capacidad de obrar, que reconocía la capacidad natural como fundamento de la capacidad de obrar legal y buscaba la máxima adecuación entre ellas: la mayoría de edad legal como presunción vendría a respaldar adecuadamente estas aspiraciones teóricas mediante la puerta que se deja abierta a la prueba de la capacidad natural en el caso concreto.

Pero más específicamente, ¿cuál es la naturaleza jurídica de la presunción iuris tantum? La doctrina es mayoritaria al sostener que las presunciones legales, si bien hacen referencia a la prueba, no se identifican con los medios de prueba, precisamente por su carácter material ${ }^{77}$, lo cual le permite surtir efectos sin necesidad de que exista proceso judicial alguno ${ }^{78}$. De este modo, puesto que la naturaleza jurídica de las presunciones judiciales se encuadra dentro de los medios de prueba ${ }^{79}$ y la naturaleza jurídica de las presunciones iuris et de iure se sitúan en el ámbito exclusivo del Derecho material ${ }^{80}$, tenemos que las presunciones iuris tantum están configuradas como un instrumento técnico en el Derecho ${ }^{81}$, mediante el cual se establece una norma de Derecho ma-

${ }^{76}$ Cfr. R. Reggi, «Presunzione. a) Diritto romano», en F. SANToro-Pasarelli (dir.), Enciclopedia del Diritto, XXXV, Giuffrè, Varese 1986, 257; cfr. E. SCAVo LOMBARDO, «Presunzione. e) Diritto canonico», en F. SANTORO-PASARELli (dir.), Enciclopedia del Diritto, XXXV, Giuffrè, Varese $1986,317$.

77 Cfr. J. Chiovenda, Principios de Derecho Procesal Civil, Tomo II, Reus, Madrid 1977, 680-681; cfr. A. S. SÁNCHEZ GIL, «Presunción»..., cit., 433.

${ }^{78}$ Cfr. L. P. Comoglio, Le prove civil..., cit., 476.

79 Cfr. J. GuasP - P. ARagoneses, Derecho Procesal Civil. I. Introducción y parte general, ThomsonCivitas, Madrid '2004, 479.

${ }^{80}$ Aunque se reconozca la posibilidad de la presunción iuris et de iure en nuestro Derecho (art. 385.3), según Guasp y Aragoneses sería dudosa que se diera en nuestro Ordenamiento, cfr. ibid., 479. En el ámbito canónico, el CIC de 1983 no las menciona siquiera, como sí hacía el CIC de 1917 (cc. 1825-1826).

81 «Toda presunción técnica es, según la terminología antigua, iuris tantum», L. PIETRo CASTRO, Derecho procesal civil, Tomo I, Librería General, Zaragoza 1946, 316. 
terial que permite la posibilidad de acudir al caso concreto para dar eficacia a una solución distinta de la prevista en la misma norma. Esto no ocurre en el resto de normas de Derecho material, donde el recurso a los jueces tiene como función hacer valer el derecho que corresponde según el supuesto de hecho previsto en la ley. En las presunciones iuris tantum puede ocurrir lo contrario.

Puesto que es un instrumento técnico de adecuación a la realidad en materias especialmente importantes, su naturaleza jurídica coincidirá con la función más determinante que tenga tanto en el ámbito material como en el procesal (el ya mencionado carácter sustantivo-procedimental de la presunción iuris tantum). En mi opinión, es aquella que describe Comoglio: «il suo effetto specifico, dunque, è quello di semplificare le fattispecie sostanziali disciplinate, agendo sulla disposizione reciproca dei loro elementi costitutivi, e solo secondariamente si rifllette sulle modalità del loro accertamento nel processo» ${ }^{82}$, y a la que apuntan buena parte de los autores con sus reflexiones ${ }^{83}$.

Tengamos en cuenta la lógica del proceso expresada con palabras de Chiovenda: «los hechos de influencia en el pleito deben ser afirmados por las partes para que el juez pueda tenerlos en cuenta; no sólo esto: tales hechos deben, regularmente, ser probados por las partes para que puedan considerarse como existentes» ${ }^{84}$. Pues bien, la presunción legal, con su previsión por el legislador, se anticipa al pleito y da como una solución adelantada ${ }^{85}$ que mientras no se discuta o se resuelva la controversia, tiene eficacia jurídica. Ésta es

${ }^{82}$ L. P. ComogLio, Le prove civil..., cit., 476. La cursiva de la cita es mía.

83 «La finalidad de la presunción es dar seguridad a situaciones jurídicas que pueden con justicia y fundamento suponerse existentes», L. PIETRO CASTRO, Derecho procesal..., cit., 315 . Y más adelante: «La presunción persigue dispensar cierta protección a determinadas situaciones jurídicas», ibid., 316; cfr. J. ChIOvenda, Principios de Derecho..., cit., 260; cfr. Á. Bonet y Navarro, «Presunciones. Derecho procesal», en Enciclopedia furídica Básica, III, Civitas, Madrid 1995, 5047; cfr. J. Montero Aroca, La prueba en el proceso civil, Thomson-Civitas, Pamplona ${ }^{2} 2011$, 93; cfr. V. GImeno Sendra - P. Morenilla Allard, Derecho Procesal Civil. I. El proceso de de declaración. Parte General, Colex, Madrid 2004, 402; cfr. D. Mendonca, Presunciones..., cit., 84, 94-95; cfr. J. AGUILó Regla, Presunciones, verdad..., cit., 18; cfr. L. PeÑa GonZalo - T. Ausín Díez, La inferencia de hechos presuntos..., cit., 101; cfr. A. Colin - H. CAPITANT, Curso elemental.., cit., 201; cfr. J. W. HeDEMAnN, Las presunciones en el Derecho, Revista de Derecho Privado, Madrid 1931, 225; cfr. A. S. SÁNCHEZ GIL, «Presunción»..., cit., 433.

${ }^{84}$ J. Chiovenda, Principios de Derecho..., cit., 258.

85 «Las presunciones indican anticipadamente una respuesta posible a la cuestión controvertida, a los efectos de producir una decisión. En otros términos: con el fin de resolver un caso, el juzgador debe, por disposición legal, tomar como cierta determinada proposición o como producido determinado estado de cosas, mientras no existan elementos de prueba en contra», D. MENDONCA, Presunciones..., cit., 83. 
la función de "simplificar" de la presunción iuris tantum, y esta es su naturaleza jurídica: instrumento técnico que conecta el nacimiento del derecho a un hecho simple y fácilmente acreditable, quedando a salvo el recurso a la prueba del hecho presunto, complejo y más difícilmente demostrable. Entonces, en las presunciones iuris tantum se ve la referencia a la prueba como uno de sus aspectos, no como el elemento determinante de su naturaleza jurídica, por lo que no puede ser calificada como 'medio de prueba'.

Pues bien, la mayoría de edad legal, no sólo reúne los elementos que la doctrina señala como partes de la presunción iuris tantum, sino que, en mi opinión, se identifca con su naturaleza jurídica, en tanto que, parafraseando el párrafo anterior, conecta el nacimiento de la capacidad de obrar legal -ejercer por sí mismo con eficacia jurídica- a la edad natural -hecho base: simple y fácilmente acreditable-, quedando a salvo el recurso a la prueba de la in/capacidad natural -hecho presunto: complejo y difícilmente demostrable-. Esta técnica existe desde el Derecho romano con la finalidad de 'simplificar' y de hacer viable el ejercicio de los derechos en el tráfico jurídico, también después de la codificación, cuya misión no ha sido tanto generar nuevas instituciones, sino canalizar con otra sistemática el mismo intrumento técnico de la edad y su naturaleza jurídica: la presunción iuris tantum de capacidad.

La mayoría de edad como presunción iuris tantum viene a ser una interpretación que permite proseguir la inercia del realismo jurídico que los canonistas han mantenido en la teoría de la persona y de la capacidad jurídica. La interpretación positivista de la mayoría de edad, habitual en el ámbito civil, aboca a un sistema de capacidad de obrar poco realista, que ha llevado a los autores a mantener un intenso debate sobre la capacidad de obrar del menor, surgiendo una tendencia favorable a reconocer un mayor peso a su capacidad natural, a la vez que se advierte la falta de soporte legal en los códigos fuera de los casos en los que específicamente se señale una edad inferior a la mayoría de edad. La previsión general de la capacidad de los menores se encuntra, en mi opinión, en la norma de la mayoría de edad entendida como presunción iuris tantum, interpretación que emerge al considerar globalmente el momento normativo y el momento judicial del régimen jurídico de capacidad de obrar, donde se constata que el menor actúa con eficacia jurídica cuando tiene capacidad natural porque sus actos no son nulos de pleno derecho. Ello im- 
pide interpretar la mayoría de edad en sentido positivista como frontera entre la capacidad (mayores) y la incapacidad de obrar (menores). Esta solución 'realista' creo que puede contribuir a superar el positivismo sin caer en el naturalismo y casuismo prejurídicos que predominaban en los pueblos primitivos.

\section{Perspectivas}

La doctrina civil ha procurado adecuar lo más posible la capacidad de obrar legal a la capacidad natural. $\mathrm{Al}$ respecto se han propuesto varias soluciones técnicas, donde los desajustes eran considerados un mal menor, por lo que se entendía que había una parte del positivismo que era irreductible por exigencias de una cierta seguridad jurídica. Sin embargo, concebir la mayoría de edad legal como presunción iuris tantum de capacidad permite una concordancia viable entre la capacidad de obrar legal y la capacidad natural, desde el momento en que ésta formaría parte de los ordenamientos al ser un elemento de la edad como presunción, en concreto el hecho presunto, cuya prioridad puede hacerse valer en el supuesto de existir un desajuste con la capacidad de obrar legal en un caso determinado.

En mi opinión, esta propuesta estaría además en continuidad con la teoría de la capacidad de obrar, con el Derecho romano, con la tradición canónica, con la teoría procesalista sobre los elementos y la función de las presunciones (iuris tantum), con el sentido de los cánones 97, 98 y 99 del CIC, y con el funcionamiento (legal-judicial) del ordenamiento canónico donde, de un modo u otro, se permite que emerja la posibilidad de que una persona con capacidad natural pueda ejercer sus derechos y deberes con eficacia jurídica. Esto requiere un examen más detenido de la remisión al Derecho civil en materia de menores e incapaces (c. $1478 \mathrm{CIC}$ ), del valor jurídico del 'uso de razón' de los menores (cc. 11, $97 \$ 2,124 \$ 1$ CIC), de la dudosa intepretación de los 7 años como presunción iuris et de iure, (c. $97 \$ 2$ CIC), del alcance de la emancipación en el ámbito eclesial (c. $98 \$ 2$ CIC), de la repercusión en el Derecho canónico de la eficacia jurídica de los actos del menor realizados con capacidad natural y sin capacidad de obrar legal en el ámbito civil y en todo caso cuando se trate de derechos personalísimos (c. 22 CIC), de la actuación notarial del párroco en la acreditación de la capacidad en los casos en los que tiene competencia, etc.

El sistema descrito, supone además una importante ventaja para la actuación judicial en el momento de examinar la capacidad natural de una persona. 
En efecto, este examen del juez encontrará en la mayoría de edad un punto de referencia claro, que evitará la arbitrariedad y facilitará la solución justa, ya que la edad legal suministrará el quantum de capacidad mínimo que la ley establece y que el juez debe respetar. Podríamos inmaginar qué disperso sería el sistema de capacidad si el juez careciera de esa referencia. Por lo tanto, en el proceso judicial, habrá incapacidad cuando la persona esté por debajo de la capacidad que la normalidad de las personas tienen en la mayor edad. A mi modo de ver, esta es la razón de las dificultades que tienen los procesos de incapacidad consensual matrimonial al no tener en cuenta la centralidad de la edad legal matrimonial, propiciado por su catalogación como impedimento, más por razones manualísticas (anteriores al CIC de 1917) que jurídicas: el proceso de incapacitación civil puede ofrecer numerosas aportaciones técnicas en el único supuesto de incapacidad que la Iglesia se ha reservado.

En este estudio me he detenido en la interpretación doctrinal de la norma de la mayoría de edad prevista en todos los códigos desde el inicio. Ésta viene a ser el eje del régimen jurídico de capacidad de obrar en los ordenamientos, y a la vez, implica el establecimiento de una técnica cuyos principios y funcionamiento serán de aplicación a todos aquellos casos en que se prevea una edad distinta de la mayoría de edad. Que se haya fijado otra edad no significa que se establezca un sistema de capacidad de obrar diverso, sino únicamente una variación en los años que se consideran más adecuados a un concreto acto jurídico. Ahora bien, será necesario un estudio pormenorizado de cada edad distinta de la mayoría de edad, para esclarecer cómo se desenvuelve en cada una la técnica de la presunción iuris tantum de capacidad. Y en este sentido, se puede adelantar, que cuando se trata del ejercicio de derechos que por naturaleza o por bautismo pertenecen a la persona, se admite la prueba en contario del mínimo de capacidad acorde con el acto en cuestión (p. e. la acreditación del uso de razón a los 6 años para recibir la primera comunión, o la dispensa de la edad en el matrimonio), aunque es preciso un desarrollo más detallado de esta perspectiva. 


\section{Bibliografía}

Aguiló Regla, J., Presunciones, verdad y normas procesales, Isegoría 35 (2006) 9-31.

Albadalejo, M., Derecho civil. I. Introducción y parte general, Edisofer, Madrid ${ }^{19} 2013$.

Albanese, B., Le persone nel diritto privato romano, Tipografía S. Montaina, Palermo 1979.

AlPA, G. - Resta, G., Le persone e la familia. I. Le persone fisiche e i diritti della personalità, UTET, Torino 2006.

Álvarez Sánchez de Movellán, P., La prueba por presunciones. Particular referencia a su aplicación judicial en supuestos de responsabilidad extracontractual, Comares, Granada 2007.

ARANGIO-RuIZ, V., Istituzioni di diritto romano, Eugenio Jovene, Napoli ${ }^{40} 1978$.

ARNDTs, K. L., Le Pandette. Volumen I. Parte Prima, Fava e Garagnani, Bologna 1882.

AsTOLFI, R., Il matrimonio nel Diritto romano preclassico, CEDAM, Padova 2002.

—, Il matrimonio nel Diritto romano classico, CEDAM, Padova 2006.

AyrinhaC, H. A. - LydON, P. J., Marriage legislation in the New Code of Canon Law, Benzinger Brothers, New York ${ }^{2} 1952$.

Bercovitz y Rodríguez Cano, R., Derecho de la persona, Montecorvo, Madrid 1976.

Besta, E., Le persone nella storia del diritto italiano, CEDAM, Pádova 1931.

Blat, A., Comentarium textus Codicis iuris canonici. Liber II. De personis, Editio altera, Roma 1921.

Bonet y Navarro, Á., «Presunciones. Derecho procesal», en Enciclopedia $7 u$ rídica Básica, III, Civitas, Madrid 1995, 5046-5048.

Bonfante, P., Instituciones de Derecho Romano, Reus, Madrid ${ }^{5} 2002$.

Burdese, A., «Età. a) Diritto romano», en C. Mortati - S. Pugliatti (dirs.), Enciclopedia del Diritto, XVI, Giuffrè, Varese 1967, 79-80.

—, Manuale di diritto privato romano, UTET, Torino ${ }^{4} 1993$.

Carnelutti, F., Notas sobre la capacidad y la incapacidad, Revista de Derecho Privado 37 (1953) 949-956.

—, Teoría general del Derecho, Revista de Derecho privado, Madrid 1941.

CARRERAS, J., Naturaleza jurídica y tratamiento de las presunciones, Revista jurídica de Catalunya 61 (1962) 491-569. 
Colin, A. - Capitant, H., Curso elemental de Derecho civil. Tomo primero, Reus, Madrid 1922.

—, Curso elemental de Derecho civil. Tomo segundo. Volumen I, Reus, Madrid 1923.

Comoglio, L. P., Le prove civili, UTET, Torino 22004.

Conte a Coronata, M., Institutiones iuris canonici. De sacramentis. Tractatus canonicus. Volumen III, Marietti, Casali ${ }^{3} 1957$.

Coriden, J. A. - Green, T. J. - Heintschel, D. E., The Code of Canon Law. A text and commentary, Geoffrey Chapman, London 1985.

Cortés, A., «Edad», en J. Otaduy - A. Viana - J. Sedano (eds.), Diccionario General de Derecho Canónico, III, Thomson Reuters Aranzadi, Cizur Menor (Navarra) 2012, 523-528.

Coviello, N., Doctrina general del Derecho civil, Uteha, Mexico D. F. ${ }^{4} 1949$.

De Castro y Bravo, F., Derecho civil de España. Tomo II. Derecho de la persona. Parte primera. La persona y su estado civil, Instituto de estudios políticos, Madrid 1952.

De Diego, C., Curso elemental de Derecho civil español común y foral. Tomo $2^{\circ}$. Parte General, Victoriano Suárez, Madrid 1927.

De Fuenmayor, A., sub c. 98, Comentario exegético al Código de Derecho canónico, I, Eunsa, Pamplona ${ }^{32002, ~ 725-727 . ~}$

DEGNI, F., Le persone fisiche e i diritti della personalità, en F. VASSALLI (dir.), Trattato di diritto civile italiano II-I, UTET, Torino 1939, 1-57.

De Lama Aymá, A., La protección de los derechos de la personalidad del menor de edad, Tirant lo Blanc, Valencia 2006.

Delmaille, J., «Age», en R. NAZ (dir.), Dictionaire de Droit Canonique, I, Librairie Letouzey et Ane, París 1935, 315-348.

Dernburg, A., Pandette. Volume $1^{o}$. Parte $1^{a}$. Parte Generale, Fratelli Bocca, Torino 1906.

De Ruggiero, R., Istitutioni di diritto civile, Principato, Milano 1953.

Di MARZO, S., Le base romanistiche del codice civile, UTET, Torino 1950.

Di Savigny, F. C., Sistema de Diritto romano attuale. Volumen terzo, Traducción di Scialoja, UTET, Torino ${ }^{2} 1900$.

Dogliotti, M., Le persone fisiche, en P. Rescigno, Trattato di diritto privato 2. Persone e famiglia. Tomo primo, UTET, Torino 1982.

Doral García, J. A., La personalidad jurídica. De la libertad formal a la libertad civil, Revista de Derecho Privado 61 (1977) 104-122.

D’Ors, Á., Derecho privado romano, Eunsa, Pamplona ${ }^{102004,} 185$. 
FalzeA, A., «Capacitá. Teoria generale», en F. Calasso (dir.), Enciclopedia del diritto, VI, Giuffrè, Varese 1960, 8-47.

Fernández de Buján, A., Capacidad. Discapacidad. Incapacitación. Modificación judicial de la capacidad, Revista Jurídica 23 (2011) 53-81.

Ferrara, F., Trattato di diritto civile italiano. Volumen I. Dottrine generali. Parte I, Athenaeum Roma, 1921.

Ferrer Ortiz, J., Los sujetos del Ordenamiento canónico, en Manual de Derecho canónico, Eunsa, Pamplona 1988, 151-177.

Gangi, C., Persone fisiche e persone giuridiche, Giuffrè, Milano 1946.

GasParRI, P., Tractatus canonicus de matrimonio. Volumen I-II, Typis Polyglottis Vaticanis, Vaticano 1932.

GeTe Alonso y CALERA, M. del C., La nueva normativa en materia de capacidad de obrar de la persona, Civitas, Madrid 1985.

Ghirlanda, G., Il diritto della Chiesa. Mistero de comunione, San Paolo, Milán ${ }^{2} 1990$.

Gimeno Sendra, V., Proceso civil práctico. Tomo IV, La Ley, Madrid ${ }^{4} 2010$.

Gimeno Sendra, V. - Morenilla Allard, P., Derecho Procesal Civil. I. El proceso de de declaración. Parte General, Colex, Madrid 2004.

Gordillo Cañas, A., Capacidad, incapacidades y estabilidad de los contratos, Tecnos, Madrid 1986.

Goubeaux, G., Traité de Droit civil. Les personnes, Librairie générale de Droit et de Jurisprudende, París 1989.

Gualazzini, U., «Età. b) Diritto intermedio», en C. Mortati - S. PugliatTI (dirs.), Enciclopedia del Diritto, XVI, Giuffrè, Varese 1967, 80-85.

Guasp, J. - Aragoneses, P., Derecho Procesal Civil. I. Introducción y parte general, Thomson-Civitas, Madrid ${ }^{7} 2004$.

Hedemann, J. W., Las presunciones en el Derecho, Revista de Derecho Privado, Madrid 1931.

Larenz, K., Derecho civil. Parte general, Edersa, Madrid 1978.

LASARTE, C., Parte general y derecho de la persona. Principios de derecho civil, Marcial Pons, Madrid ${ }^{17} 2011$.

LeTE Del Río, J. M., Título XI. De la mayor edad y de la emancipación, en M. ALBADALEJo (dir.), Comentarios al Código civil y compilaciones forales, IV, Edersa, Madrid ${ }^{2} 1985$, 495-508.

Lombardía, P., Escritos de Derecho canónico I, Eunsa, Pamplona 1973. 
LÓPEZ AZCONA, A., La peculiar situación jurídica del menor aragonés mayor de catorce años, Actualidad Jurídica Iberoamericana 2 (2015) 453-465.

LÓpez SAN LuIs, R., La capacidad contractual del menor, Dykinson, Madrid 2001.

Lorca Navarrete, A. M., Tratado de derecho procesal civil. Parte general. El nuevo proceso civil, Dykinson, Madrid 2000.

Mans Puigarnau, J., Derecho matrimonial canónico. Volumen I, Bosch, Barcelona 1959.

Marrone, M., Manuale di diritto privato romano, Giappichelli, Torino 2004.

MARTíneZ DE AguiRRE y ALDAZ, C., La protección jurídico-civil de la persona por razón de la menor edad (Una aproximación teleológica a las instituciones de asistencia y protección de menores en nuestro Derecho civil), Anuario de Derecho Civil 45 (1992) 1391-1498.

—, La persona y el Derecho de la persona, en P. DE Pablo Contreras (coord.) Curso de Derecho civil. Volumen I. Derecho privado. Derecho de la persona, Colex, Madrid ${ }^{42011,319-330 .}$

—, La edad, en P. De Pablo Contreras (coord.), Curso de Derecho civil. Volumen I. Derecho privado. Derecho de la persona, Colex, Madrid ${ }^{42011,397-422 .}$

- $s u b$. 314-324 Cc, en P. De Pablo Contreras - R. Valpuesta FernánDEZ, Código civil comentado, I, Civitas-Thomsom Reuters, Navarra 2011, 1323-1339.

Messineo, F., Manuale di diritto civile e commerciale, Giuffrè, Milano ${ }^{9} 1957$.

Michiels, G., Normae Generalis Iuris Canonici, Sant Ioannis Evangelistae, Roma 1949.

—, Principia Generalia de personis in Ecclesia, S. Joannis Evangelistae, Roma 1955.

Montejo Rivero, J. M., Menor edad y capacidad de ejercicio: reto del derecho familiar contemporáneo, Revista sobre la infancia y la adolescencia 2 (2012) 2336, en http://dx.doi.org/10.4995/ reinad.2012.1036.

Montero Aroca, J., La prueba en el proceso civil, Thomson-Civitas, Pamplona ${ }^{6} 2011$.

Montero y GutiÉRrez, E., El matrimonio y las causas matrimoniales, Sáez, Madrid ${ }^{7} 1965$.

Nieto Alonso, A., Capacidad del menor de edad en el ordenamineto patrimonial civil y alcance de la intervención de sus representantes legales, Revista de Derecho civil 3 (2016) 1-47, en http:// nreg.es/ojs/index.php/RDC.

ONDEI, E., Le persone fisiche e i diritti della personalità, UTET, Torino 1965. 
Ortells Ramos, M., Derecho procesal civil, Thomson-Aranzadi, Pamplona ${ }^{8} 2008$.

PeÑa Gonzalo, L. - Ausín DíEz, T., La inferencia de hechos presuntos en la argumentación probatoria, Anuario de Fisolofía del Derecho 18 (2001) 95-125.

Pérez de Castro, N., El menor emancipado, Tecnos, Madrid 1988.

Petroncelli, M., Diritto canonico, Jovene, Nápoles ${ }^{8} 1983$.

Pietro Castro, L., Derecho procesal civil, Tomo I, Librería General, Zaragoza 1946.

Planiol, M., Traité Pratique de Droit Civil Français. Tome I. Les persones, Libraire générale de droit et de jurisprudence, Paris 1925.

Putg Brutau, J. - Puig Ferriol, L., Fundamentos de Derecho civil. Tomo I. Volumen I. Parte General. Sujeto y objeto del Derecho, Bosch, Barcelona 1979.

Ramos Chaparro, E., La persona y su capacidad civil, Tecnos, Madrid 1995.

RAMPONI, L., La teoria generales delle presunzioni nell diritto civile italiano, Bocca, Roma 1890.

Ravà, A., Istituzioni di diritto privato. II. Diritto delle persone, CEDAM, Padova ${ }^{5} 1932$.

Ravetllat Ballesté, I., ¿¿Por qué dieciocho años? La mayoría de edad civil en el ordenamiento jurídico civil español, Anales de la Cátedra de Francisco Suárez 49 (2015) 129-154.

Regatillo, E. F., Derecho matrimonial eclesiástico, Sal Terrae, Santander 1962.

RegGi, R., «Presunzione. a) Diritto romano», en F. SANTORO-PASARELli (dir.), Enciclopedia del Diritto, XXXV, Giuffrè, Varese 1986, 255-260.

Rescigno, P., «Capacità di agire», en A. AZARA - E. Eula, Novissimo Digesto Italiano, II, UTET, Torino ${ }^{3} 1957,861-867$.

Roberti, M., Svolgimento storico del diritto privato in Italia. I, CEDAM, Pádova $^{2} 1935$.

Ruperto, C., «Età. c) Diritto privato», en C. Mortati - S. PugliatTi (dirs.), Enciclopedia del Diritto, XVI, Giuffrè, Varese 1967, 85-92.

SÁNCHEZ GIL, A. S., La presunzione di validità dell'atto giuridico nel diritto canonico, Giuffrè, Milano 2006.

—, «Presunción», en J. Otaduy - A. Viana - J. Sedano (eds.), Diccionario General de Derecho Canónico, VI, Thomson Reuters Aranzadi, Cizur Menor (Navarra) 2012, 425-433.

Sancho Rebullida, F. de A., Estudios de Derecho civil II, Eunsa, Pamplona 1978. 
Scaevola, Q. M., Código civil comentado y concordado extensamente. Tomo I, Moreno y Rojas, Madrid 1889.

Scavo Lombardo, E., «Presunzione. e) Diritto canonico», en F. SANToroPasarelli (dir.), Enciclopedia del Diritto, XXXV, Giuffrè, Varese 1986, 316321.

SCIASCIA, G., «Capacità giuridica. Diritto romano», en A. AZARA - E. EUlA, Novissimo Digesto Italiano, II, UTET, Torino ${ }^{3} 1957,869-871$.

STANZIONE, P., Capacità e minore età nella problematia della persona umana, Jovene Editore, Camerino 1976.

—, Persona fisica. Diritto civile, en G. Autorino Stanzione - P. Stanzione, Diritto civile e situazioni esistenziale, Giappichelli, Torino 1997, 11-26.

TAFAro, S., Pubes et viripotens nella esperienza giuridica romana, Cacucci, Bari 1988.

Tena Piazuelo, I., La capacidad para realizar actos con eficacia jurídica, en la jurisprudencia, en S. DE SALAS MuRILlo (coord.), Hacia una visión global de los mecanismos jurídico-privados de protección en materia de discapacidad, El Justicia de Aragón, Zaragoza 2010, 125-184.

Torres-Dulce, M. Á., Cánones y leyes de la Iglesia. Nociones fundamentales, $\mathrm{Pa}$ labra, Madrid 2017.

TRIFONE, R., Le persone e le classi sociali nella storia del diritto italiano, Nicola Jovene, Napoli ${ }^{2} 1933$.

Valpuesta Fernández, M. del R., El Derecho civil. Codificación y Constitución, en Derecho Civil. Parte general. Derecho de la persona, Tirant lo Blanc, Valencia ${ }^{4} 2003$.

Valverde y Valverde, C., Tratado de derecho español. Tomo I. Parte General, Cuesta, Valladolid ${ }^{3} 1925$.

Veermeersch, A. - Creusen, J., Epitome iuris canonici. Tomus II, Mechlinlae, Bruxelles ${ }^{6} 1940$.

Wernz, F. W. - VIDAL, P., Ius canonicum. Tomo V. Ius matrimoniale, Universitatis Gregorianae, Romae 1925.

WindscheID, B., Diritto delle pandette, Unione Tipografica, Milano 1902. 